\title{
Development of a Point Pyroshock Source Simulator
}

\author{
Ju-won Jeong, ${ }^{1}$ Jae hyuk Lim, ${ }^{2}$ Kyung-won Kim, ${ }^{3}$ and Jung-ju Lee ${ }^{1}$ \\ ${ }^{1}$ Department of Mechanical Engineering, Korea Advanced Institute of Science and Technology (KAIST), \\ Daejeon 34141, Republic of Korea \\ ${ }^{2}$ Department of Mechanical Engineering, Chonbuk National University, Jeonju 54896, Republic of Korea \\ ${ }^{3}$ Satellite Mechanical Team, Korea Aerospace Research Institute (KARI), Daejeon 34133, Republic of Korea
}

Correspondence should be addressed to Jung-ju Lee; leejungju@kaist.ac.kr

Received 11 October 2016; Accepted 7 December 2016; Published 6 February 2017

Academic Editor: Georges Kouroussis

Copyright $\odot 2017$ Ju-won Jeong et al. This is an open access article distributed under the Creative Commons Attribution License, which permits unrestricted use, distribution, and reproduction in any medium, provided the original work is properly cited.

We developed a point pyroshock source simulator (PPSS) for the study on the source isolation approach (SIA) in this study. In spite of the potentiality of the SIA for avionics protection against pyroshock, it has rarely been investigated due to lack of pyroshock source simulators. To overcome such a situation, we proposed the PPSS using a mechanically excited tuned resonator simulating a release device itself. The PPSS was designed using explicit finite element analysis and Seigel's gas gun model. To verify the proposed PPSS, the prototype was fabricated and tested. From the results, we have shown that the prototype of the PPSS simulates a near-field pyroshock and is able to evaluate the SIA.

\section{Introduction}

Many separation events occur in aerospace systems: stage separation of a space launch vehicle, a separation between a spacecraft and a space launch vehicle, and solar array deployment from a satellite. These separation processes are carried out by various release devices. In particular, the operation of release devices emits pyroshock which is basically a broadband high frequency stress wave. At the beginning of the space race, Titan I and Atlas, first generation intercontinental ballistic missiles, exploded on the launch pad due to relay malfunction in the safety destruct system induced by pyroshock $[1,2]$. After the first report of pyroshock induced failure in the early 1960s, many pyroshock induced failures have continuously occurred. The number of pyroshock induced failures is 14 times greater than that of vibration induced failures. Furthermore, approximately $70 \%$ of the pyroshock induced failures resulted in catastrophic loss of mission [3]. It was revealed that the main cause is the vulnerability of avionics to pyroshock. For this reason, avionics require pyroshock testing and they are commonly mounted through isolators if they cannot survive under pyroshock environments: isolating avionics is called an equipment isolation approach (EIA) as illustrated in Figure 1.
The EIA is a well-developed method for avionics protection against pyroshock. The key principle of the EIA is the mechanical low-pass filter effect of conventional rubber isolators induced by their low stiffness $[4,5]$. Although they can efficiently isolate avionics from pyroshock, their low stiffness may make avionics susceptible to both quasi-static flight loads and structural vibration below $100 \mathrm{~Hz}[6,7]$. Furthermore, sway-space, electrical or thermal groundings, and equipment alignment should be also considered. Due to these reasons, design of an isolated avionic equipment requires 25 steps [6]. In contrast, a source isolation approach (SIA) can be an ultimate solution for avionics protection against pyroshock because it provides early protection prior to propagation of pyroshock, as shown in Figure 1. Such a characteristic of the SIA is expected to minimize the required number of isolation treatments without any negative influences on avionics.

However, few studies on the SIA were carried out mostly by using actual flight structure and pyroshock sources [2, $8-12]$. It is costly and time-consuming to develop source isolators using full-scale or actual system and thus a suitable pyroshock simulator is essential to investigate the SIA. Indeed, the prerequisite for the study on the SIA is a pyroshock source simulator which, like an actual source, 

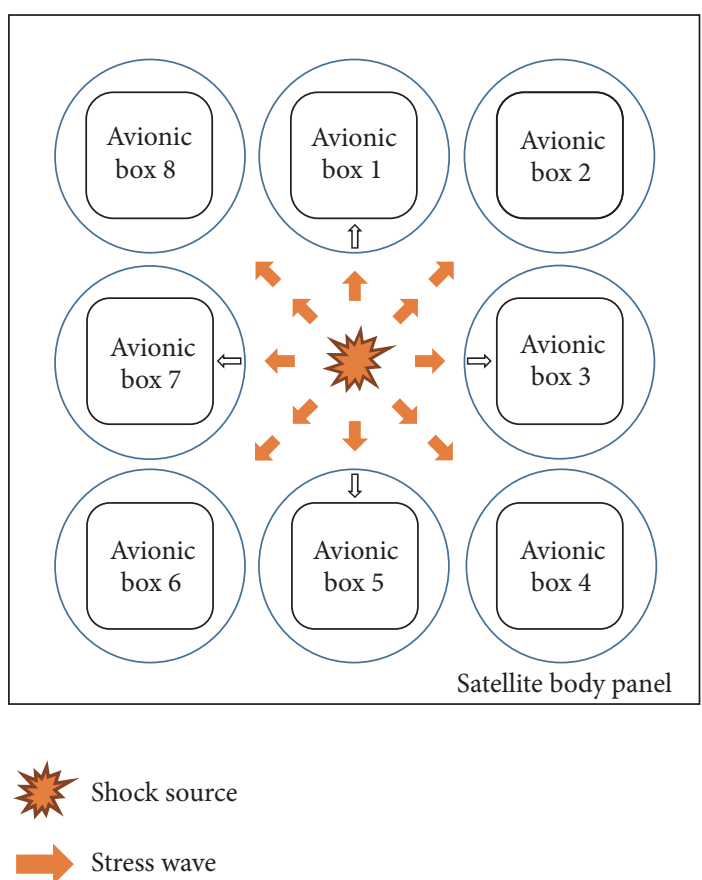

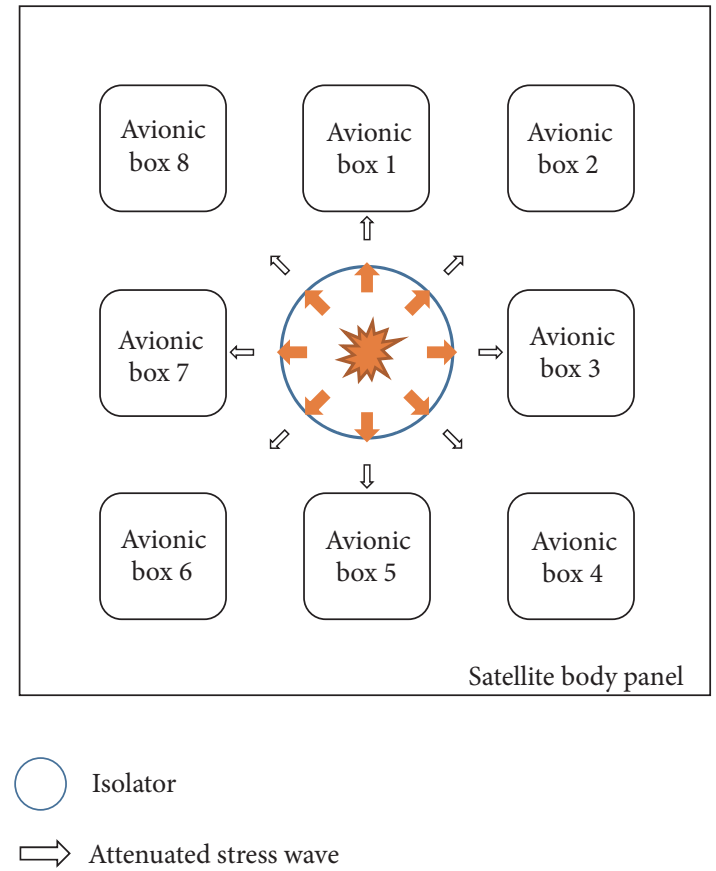

(b)

FIgure 1: Comparison between the EIA and the SIA. (a) The EIA. (b) The SIA.

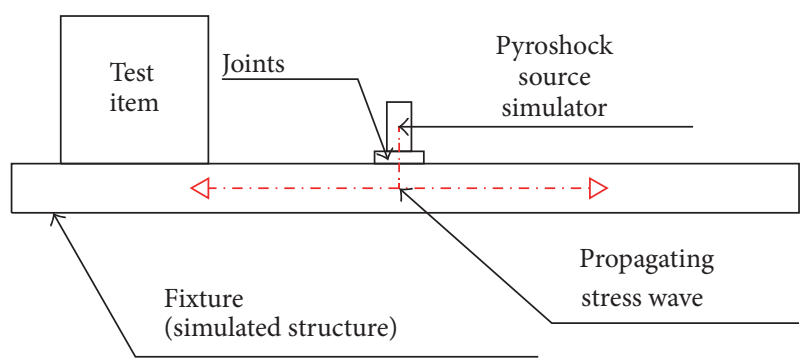

FIgURE 2: Concept of a pyroshock source simulator.

generates stress waves propagating on its fixture (a simulated structure) and has bolted joints for attachment, as shown in Figure 2. Note that source isolators can be inserted into the joints between an actual source and its structure so that pyroshock could be absorbed or reflected before propagation. But the previous pyroshock simulators such as electrodynamic shakers and mechanically excited resonant fixture techniques shown in Figure 3 are fundamentally based on their vibrating fixtures whose response satisfies the shock response spectrum (SRS) requirements [13-22]. In other words, their dominant behavior is not stress wave propagation but vibration of the whole fixture. Another simulation method, pyrotechnically excited resonant fixture techniques, is suitable to simulate stress wave propagation near a pyroshock source but they do not have joints like an actual source [13-16, 23]. Above all, they inherently have low repeatability and are costly due to use of an explosive charge.
Recently, Dilhan et al. developed a gun-like pyroshock generator using an explosive charge [24]. It is a good pyroshock generator satisfying their intention, but its stress wave directly propagates on its fixture in the same manner as conventional pyrotechnically excited resonant fixture techniques.

Bateman and Titulaer developed pneumatic pyroshock simulators to investigate source isolators for V-band clamps (shown in Figure 4) which are a pyroshock source having the characteristics of both point and line sources $[25,26]$. These simulators provide the simulation of pyroshock induced by a V-band clamp and also have joints so that source isolators could be inserted. However, according to authors' best knowledge, there are no pyroshock simulators suitable to investigate the SIA for point sources such as explosive bolts, separation nuts, and pin-pullers. As previously mentioned (Figure 2), a real point source itself should be simulated so that source isolators could be inserted between the simulated point source and structure. Therefore, the goal of this work is to develop a point pyroshock source simulator (PPSS) by using a tuned bar-type resonator excited by a pneumatically propelled projectile. This tuned resonator generates stress waves radially propagating on a simulated structure, and source isolators can be inserted between the resonator and the simulated structure for evaluation of their pyroshock attenuation. The energy of the stress waves is concentrated at the knee frequency of a target environment especially, thereby minimizing the required trials and errors for tuning the knee frequency of the PPSS. The PPSS was designed using a systematic design procedure based on explicit finite element analysis (FEA) and Seigel's preburned propellant ideal gas gun (PPIG) model [27]. According to the design result, 


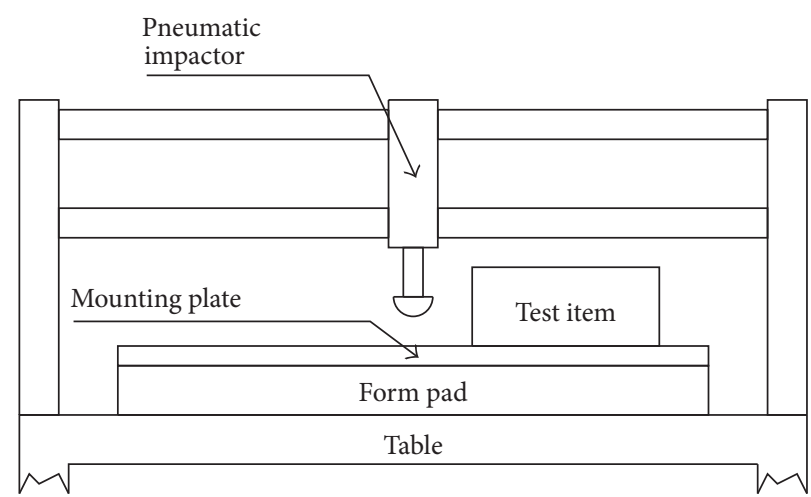

(a)

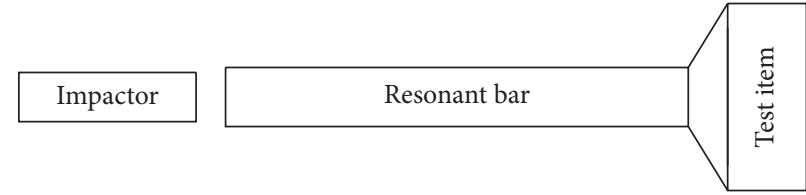

(b)

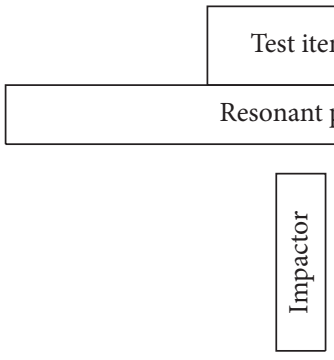

(c)

FIgURE 3: Schematic diagrams of resonant fixture techniques. (a) MIPS (mechanical impact pyroshock simulator). (b) A bar-type tuned resonant fixture. (c) A plate-type tuned resonant fixture.

we fabricated the prototype for verification. The simulation target of the PPSS was the pyroshock environment generated by the ESA M6 pyrotechnic separation nut and three simulated environments were effectively equivalent to the target with high repeatability. To confirm the functionality of the PPSS as a source isolator evaluator, we tested the SIA tried during Viking program. The principle of the SIA is improvement of joint attenuation by inserting spacers into pyroshock path and the typical characteristic of the SIA is spectrum peak attenuation. In the test on the SIA using the PPSS, the spectrum peak attenuation was clearly observed, thereby confirming the functionality of the PPSS as a source isolator evaluator. The characteristics of the proposed PPSS are summarized in Table 1, including comparison of the previous simulators.

\section{Conceptualization}

The major aim of the PPSS is to simulate an actual point pyroshock source itself for study on the SIA. To pursue high repeatability, low operating cost, and efficient operation, we planned to use metal-to-metal impact as means of pyroshock generation, not both an explosive charge and an actual release device. Figure 5 shows our target environment produced from an M6 pyrotechnic separation nut and ALU bench of the European Space Agency (ESA) [28]. ALU bench is a freely suspended aluminum plate whose dimensions are $1,000 \mathrm{~mm} \times 1,000 \mathrm{~mm} \times 5 \mathrm{~mm}$ and is a standard pyroshock test bench of ESA to characterize various release devices. ALU bench simulates the wall plate of a satellite at which avionic boxes and a pyroshock source are attached. For consistency, a fixture identical to ALU bench was intended to be applied to the PPSS in that structure configuration strongly influences pyroshock intensity. The main difference between ALU bench and the PPSS is that a release device simulator module generates pyroshock instead of actual sources. This makes efficient and low cost testing possible because release devices are quite costly and their pyroshock environments are not inherently repeatable.

Generally, it is impossible to make a simulated pyroshock environment completely identical to that of a target. Thus, standards such as NASA-STD-7003A [29] and MIL-STD810G [30] provide tolerance guidelines for pyroshock simulation. According to the two standards, a simulated environment is regarded effectively equivalent if the following is satisfied: the simulated SRS magnitudes are within the tolerances (SRS tolerance condition), and at least $50 \%$ of them are larger than the nominal specification (SRS magnitude condition). We set the tolerances according to NASA-STD7003A, as shown in Figure 5.

2.1. Preliminary Design. The components of the PPSS are a release device simulator module, a launcher, a freely suspended plate-type fixture (ALU bench), and instrumentation, as shown in Figure 6. The key component is the release device simulator module consisting of a tuned resonator, a sacrificial plate, and a projectile. Also, a dummy mass can be added for simulation of an avionic box if required. 
TABLE 1: Comparison of the PPSS with the other pyroshock simulators.

\begin{tabular}{lccccr}
\hline Simulator & Simulation target & Simulated field & Resonator & Joint simulation & Excitation \\
\hline MERFT $^{\text {a }}$ & Only pyroshock environment at the & Far and mid & No & No & Mechanically \\
PERFT $^{\text {b }}$ & mounting point of avionics & Near & No & No & Pyrotechnically \\
VBS $^{\mathrm{c}}$ & V-band & Mid & Yes & Yes & Mechanically \\
PPSS $^{\text {d }}$ & Point sources & Near & Yes & Yes & Mechanically \\
\hline
\end{tabular}

${ }^{a}$ Mechanically excited resonant fixture technique [13-22].

${ }^{\mathrm{b}}$ Pyrotechnically excited resonant fixture technique [13-16, 23].

${ }^{c} \mathrm{~V}$-band simulator $[25,26]$.

${ }^{\mathrm{d}}$ Point pyroshock source simulator (still not developed).

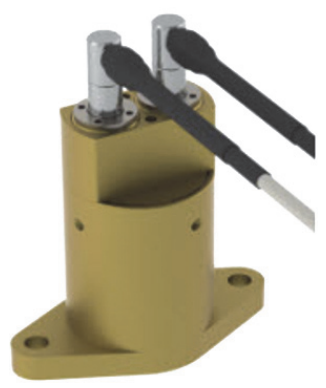

(a)

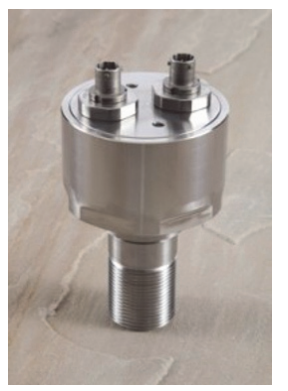

(b)

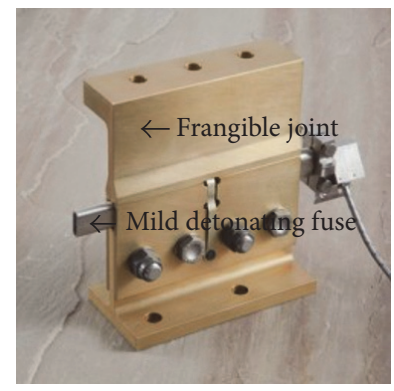

(c)

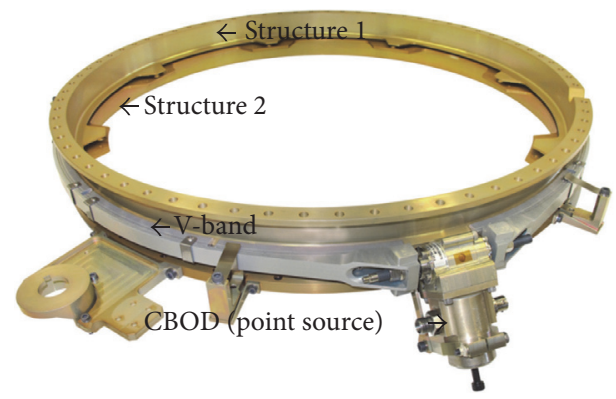

(d)

FIgUre 4: Point sources: (a) separation nut and (b) explosive bolt; line source: (c) frangible joint; combined source: (d) V-band clamp.

2.1.1. Release Device Simulator Module. The impacted resonator generates a radially propagating stress wave on ALU bench. Note that the dominant frequency of the stress wave is determined by the first longitudinal natural frequency of the resonator. Thus, the SRS knee frequency of the PPSS can be matched to that of the target environment without trials and errors, by adjusting the length of the resonator. Also, the

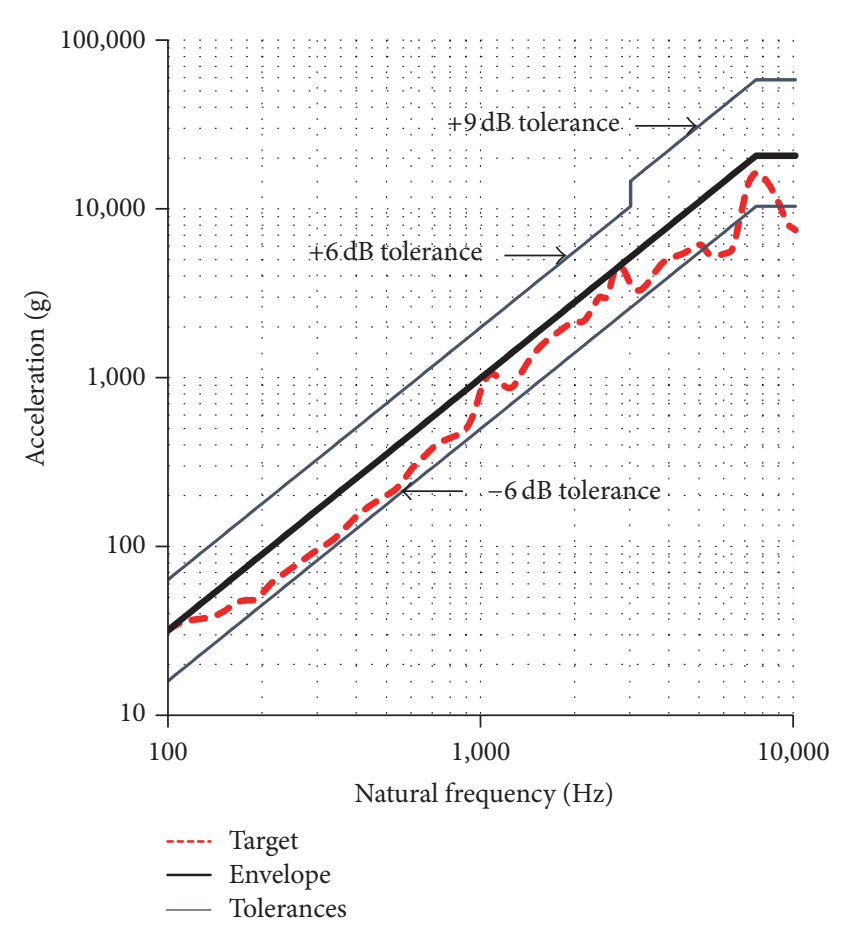

FIgURE 5: Target pyroshock environment (the target data was taken from [28]). The tolerances are $\pm 6 \mathrm{~dB}$ up to $3 \mathrm{kHz}$ and $+9 \mathrm{~dB} /-6 \mathrm{~dB}$ for natural frequencies above $3 \mathrm{kHz}$ according to NASA-STD-7003A [29].

resonator also provides two bolt joints like release devices so that source isolators could be inserted into the two bolt joints for performance evaluation of source isolators, as shown in Figure 7. In the case of the EIA, it can be evaluated by using a dummy mass in the same manner. To ensure the repeatability of the PPSS, the sacrificial plate should be attached to the impacted end of the resonator and be replaced for each test.

2.1.2. Launcher. Considering that pyroshock results in essentially no velocity change in the mounting structure of a release device [30], simulated pyroshock environments should also have such a characteristic. To this end, it is necessary to use a light projectile having high speed. Pneumatic energy can be highly concentrated as a form of compressed air, thereby transferring the concentrated energy to the projectile kinetic energy. In contrast, a projectile propelled by elastic members 


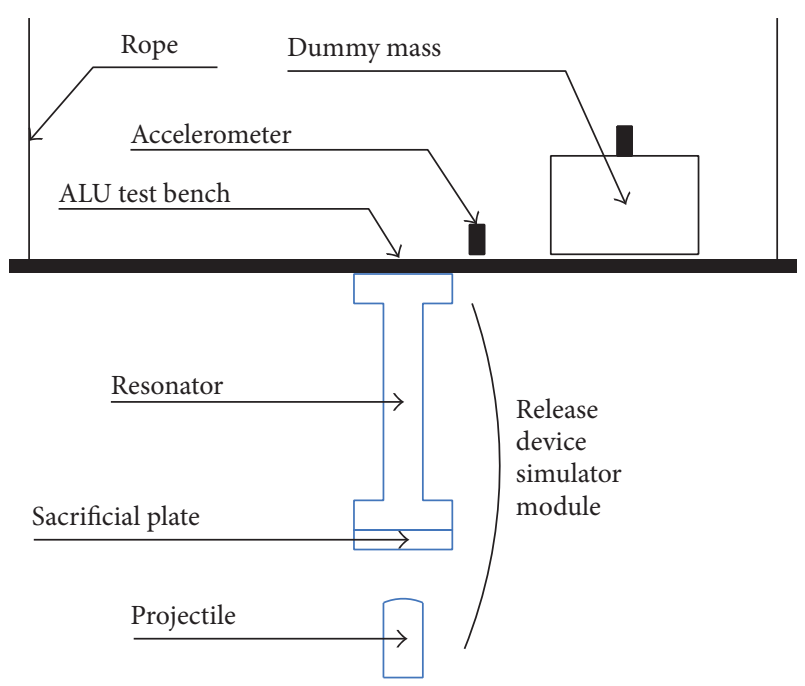

FIgURE 6: Schematic diagram of the PPSS.

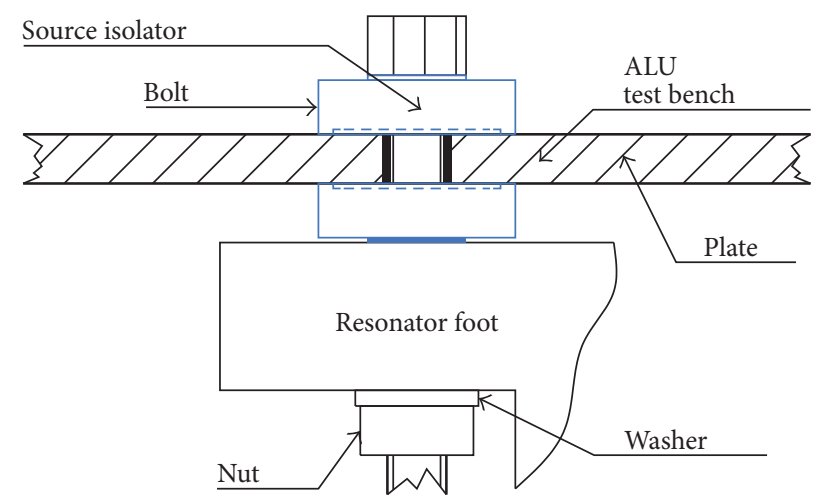

Figure 7: Performance evaluation of source isolators using the PPSS.

is inefficient because the elastic members consume most of their stored strain energy to move themselves. Another candidate, gravitational potential energy, requires a quite tall structure for a high speed impactor. Therefore, the most suitable method is a pneumatically propelled projectile.

There are three air gun mechanisms available for pyroshock testing: a solenoid valve breech $[35,36]$, a burst diaphragm breech [37-39], and a wrap-around breech [3841]. Among these mechanisms, we considered the wraparound breech mechanism as the best candidate due to its rapid breech opening and robustness to shockwave. The solenoid type cannot have such characteristics although the breech opening time is an important factor in the performance of air guns [42] and shock can occur due to the impact between the barrel and the projectile. The burst diaphragm breech could be candidate; however, it consumes its diaphragm in each test, thereby requiring disassembly to replace the diaphragms. Note that a muzzle should be added to the wrap-around breech to not only catch the returning projectile but also remove the remaining pressure before the projectile returns.
TABLE 2: Instrumentation requirements for pyroshock measurement $[13,16,29-33]$.

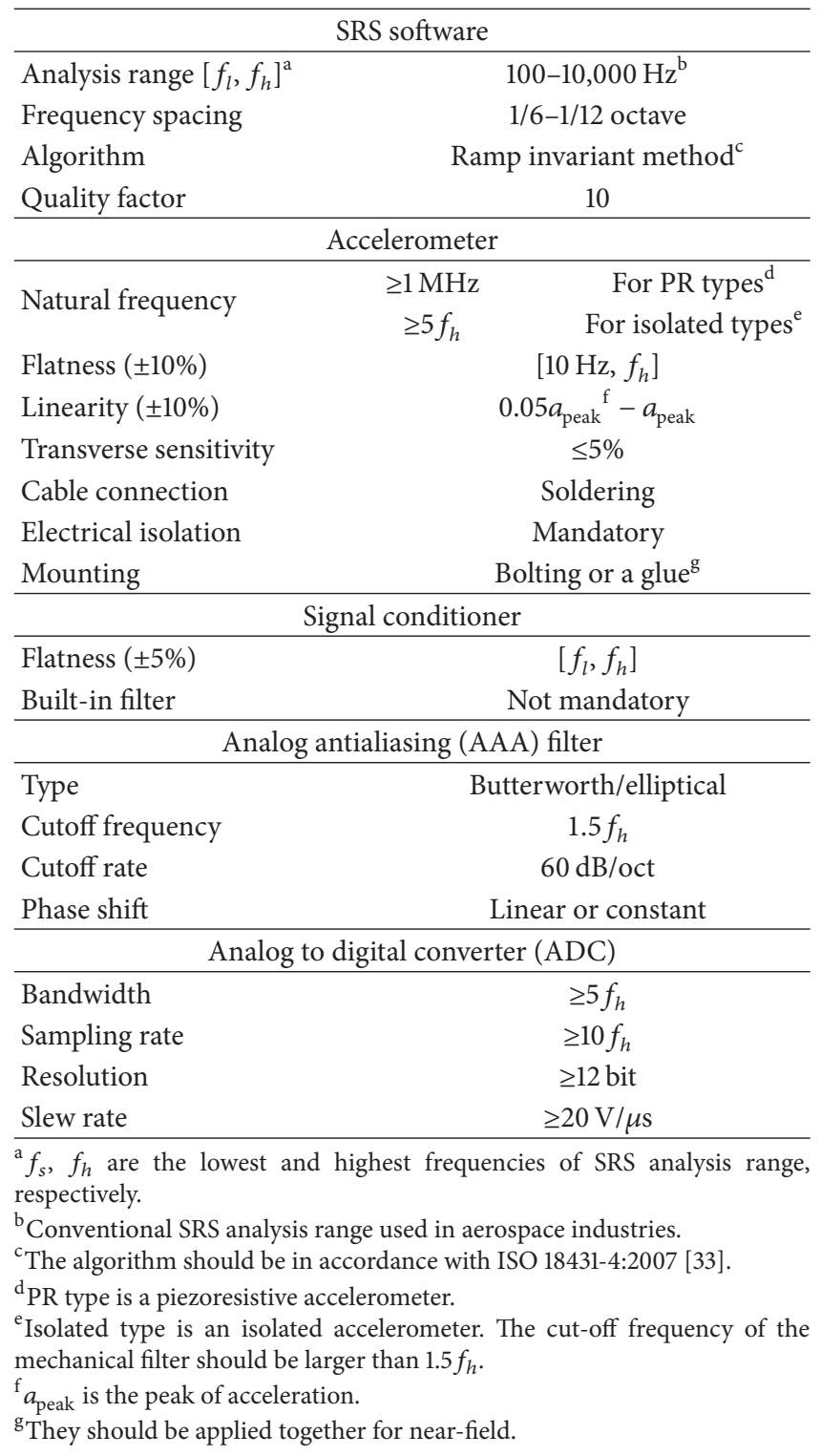

2.1.3. Instrumentation. Pyroshock measurement is challenging because of the high frequency contents of pyroshock. There are many problems in pyroshock measurement $[13,16$, 29, 31, 32]: resonance and overloading of accelerometers, saturation of signal conditioners, aliasing, and so on. Referring to the following references [13, 16, 29-33], we summarized the recommended requirements for pyroshock measurement in Table 2, including those of SRS software.

2.2. Design Procedure. The PPSS can be sequentially designed in the following order: a release device simulation module, air gun capacity determination, and instrumentation.

2.2.1. Release Device Simulator Module. The release device simulation module should be designed so that the simulated SRS could match that of the target environment. The SRS 
TABLE 3: Design variables of the release device simulator module.

\begin{tabular}{lccc}
\hline \multirow{2}{*}{ Component } & \multicolumn{2}{c}{ Initially defined variables } & \multirow{2}{*}{ Major variable } \\
& Parameter & Value & \\
\hline \multirow{3}{*}{ Resonator } & $W_{R}$ & $30 \mathrm{~mm}$ & \\
& $L_{f}$ & $30 \mathrm{~mm}$ & $L_{R}$ \\
& $h_{f}$ & $15 \mathrm{~mm}$ & \\
& Material & $S C M ~ 435^{\mathrm{a}}$ & \\
\multirow{2}{*}{ Projectile } & $\Phi_{p}$ & $20 \mathrm{~mm}$ & $v_{P}$ \\
& $L_{p}$ & $40 \mathrm{~mm}$ & \\
& $R_{P}$ & $200 \mathrm{~mm}$ & - \\
Sacrificial plate & $h_{S}$ & $10 \mathrm{~mm}$ & \\
& Material & SNCM 440 & \\
\hline
\end{tabular}

${ }^{\mathrm{a}}$ Heat-treated.

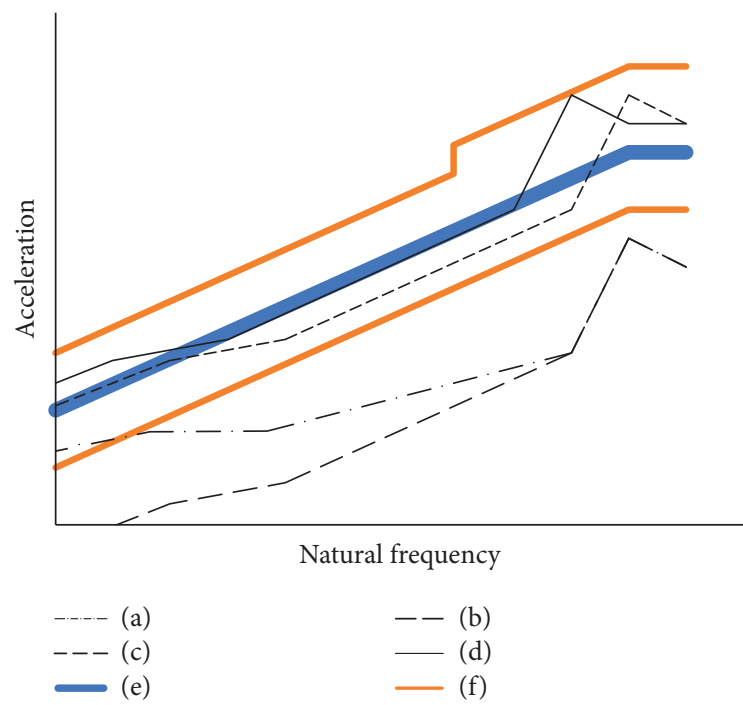

FIGURE 8: Schematic diagram of SRS matching procedure. (a) Initially obtained SRS after knee frequency tuning. (b) Slopeadjusted SRS. (c) Scaled SRS. (d) Retuned SRS. (e) Nominal test specification. (f) Tolerances.

matching procedure consists of five steps shown in Figure 8: assigning a target pyroshock environment, tuning the knee frequency of the PPSS to that of the target, matching the SRS slopes in the ramp region, scaling the projectile energy, and retuning the knee frequency of the PPSS to satisfy the SRS magnitude condition. The design variables are described in Figure 9. Except for projectile velocity $v_{P}$ and resonator length $L_{R}$, we determined their values in a qualitative manner taking into consideration an alignment problem and the dimensions of release devices commonly used in Korean satellites (the values are shown in Table 3 ). In contrast, $v_{P}$ and $L_{R}$ should be quantitatively determined because they are most influential in the knee frequency and intensity of the simulated environment.

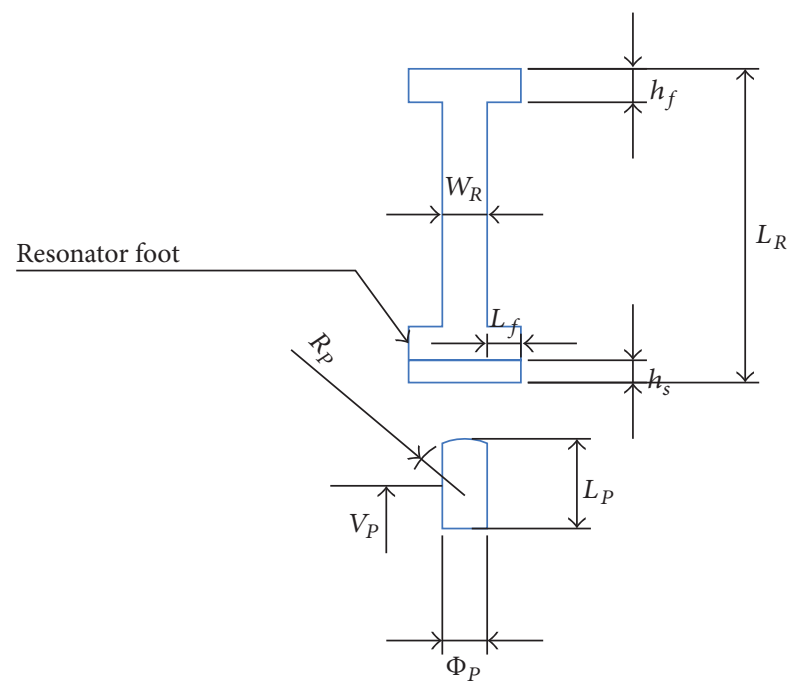

FIGURE 9: Design variables of the release device simulator module. $W_{R}$ : the resonator width, $h_{f}$ : the resonator foot thickness, $L_{f}$ : the resonator foot length, $L_{R}$ : the resonator length, and $h_{s}$ : the thickness of the sacrificial plate. $L_{p}$ : the projectile length, $R_{p}$ : the radius of curvature (ROC) at the impacted end of the projectile, $\Phi_{p}$ : the projectile diameter, and $v_{P}$ : the projectile velocity.

The first step of SRS matching, tuning the knee frequency of PPSS $f_{\text {PPSS }}$ to that of the target, is simply possible by using the following:

$$
f_{\mathrm{PPSS}} \sim \frac{1}{\sqrt{2}} f_{\mathrm{bar}}=\frac{1}{\sqrt{2}} \frac{c}{2 L_{R}}=\frac{1}{\sqrt{2}} \frac{\sqrt{E / \rho}}{2 L_{R}},
$$

where $f_{\text {bar }}$ and $c$ are the first natural frequency of a free-free bar and the longitudinal phase speed, respectively; $E$ and $\rho$ are elastic modulus and density of the resonator material. $L_{R}$ is determined so that $f_{\text {PPSS }}$ could match the knee frequency of the target. The rough equation (1) was derived assuming the vibration of ALU bench near the resonator is synchronized with that of the resonator in addition to using Dunkerley's method [43]. After the first step, the initial SRS is evaluated using explicit FEA with an arbitrary but seemingly suitable $v_{p}$ ( $v_{p}$ is iteratively determined by the design procedure shown in Figures 8 and 10).

Usually, the second step, matching the SRS slopes, is not required. Otherwise, it can simply be finished by trying a much lighter projectile.

In the third step, to push the SRS magnitudes into the region within the tolerances, the SRS should be shifted uniformly over the whole frequency range of SRS analysis. This is achieved by scaling the projectile energy. For the current velocity $v_{P, r}$ and the SRS magnitudes $\mathrm{SRS}_{r}$, one can obtain the velocity required to satisfy the scaled SRS magnitudes $\mathrm{SRS}_{n}$, as follows:

$$
v_{P, n}=\frac{\operatorname{SRS}_{n}(d)}{\operatorname{SRS}_{r}(d)} v_{P, r}
$$




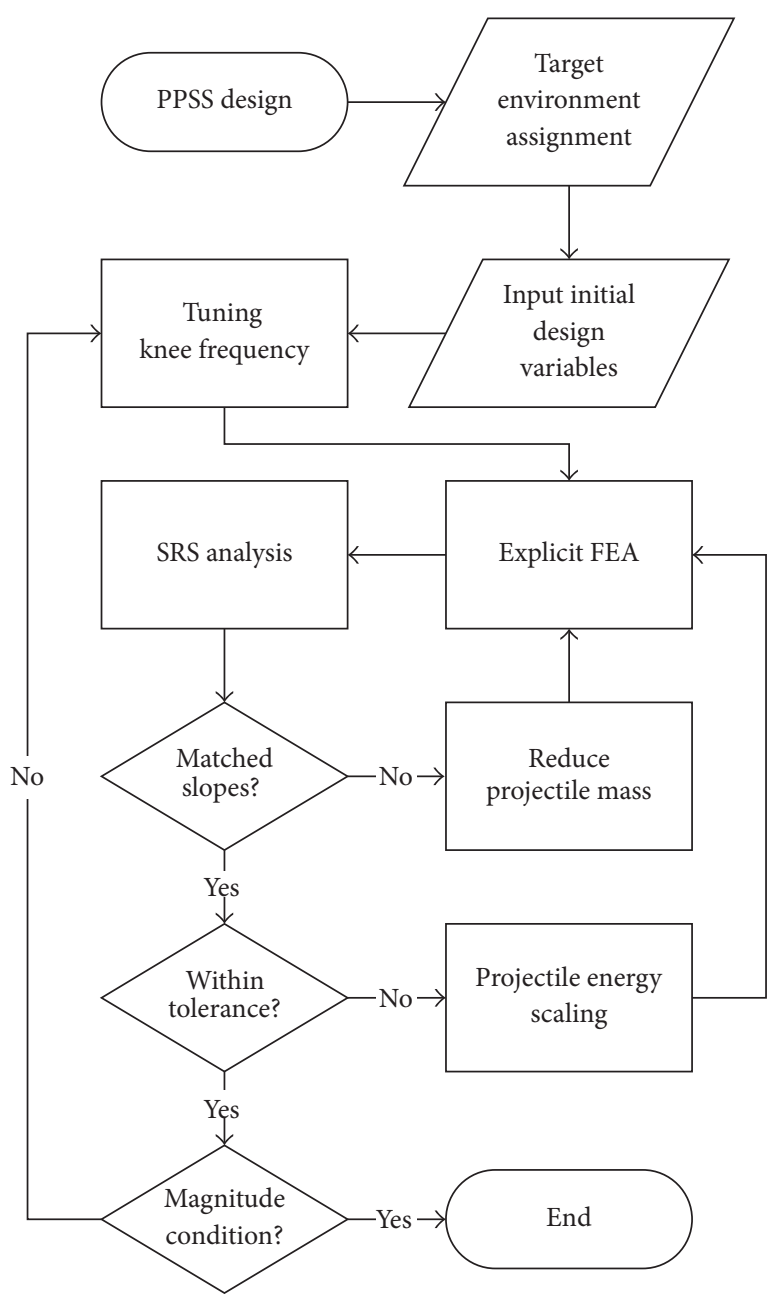

FIGURE 10: Flow chart for the development of the release device simulator module.

where $d$ is the distance from the resonator. This equation was obtained, referring to source energy scaling equation $[15,29,30]$. After scaling the projectile energy, explicit FEA refines the shifted SRS magnitudes. This step may require few iterations as shown in Figure 10, due to the plastically absorbed energy of the sacrificial plate.

The final step, satisfying the magnitude condition, can be finished by slightly reducing $f_{\text {PPSS }}$ with help of the first order Taylor approximation of (1) at the current resonator length $L_{R, r}$.

$$
L_{R, n} \approx L_{R, r}+\frac{\sqrt{8} L_{R, r}^{2}}{c}\left(f_{\mathrm{PPSS}, r}-f_{\mathrm{PPSS}, n}\right) .
$$

2.2.2. Air Gun Capacity Determination. According to the design result of the release device simulation module, the air gun should accelerate the projectile up to the required velocity. The capacity and corresponding configuration of the air gun can be determined by Seigel's PPIG model. This will be discussed in the next section.

\section{Detailed Design}

In this section, we explain the explicit FEA model for the PPSS, Seigel's PPIG model, and the instrumentation in detail. We used Abaqus Explicit (version 6.10) as an explicit FEA solver. First, the SRS software is described.

3.1. SRS Software. There is an excellent SRS software developed by Irvine [44]. It is completely consistent with ISO 18431-4:2007 [33] but may not be compatible with the acceleration data from Abaqus Explicit. In general, the data from Abaqus Explicit have irregular time increments due to the automatic time incrementation of Abaqus Explicit. Thus, to perform SRS analysis on the data from Abaqus Explicit, we added time increment regularization to Irvine's software, referring to Diehl's recommendation [45]. A digital resampling process was also included to minimize the inherent error of the ramp invariant algorithm in ISO 18431-4:2007. The error can be predicted as follows:

$$
e_{\text {total }}=\left\{1-\left[\frac{\sin \left(\pi R_{s}\right)}{\pi R_{s}}\right]^{2}\right\}+\left[1-\cos \left(\pi R_{s}\right)\right]
$$

The first and second terms in (4) are the bias and data sparsity errors, respectively [33,46]. Using (4), a suitable resampling rate can be obtained for a required error limit. For example, the SRS from data sampled with $100 \mathrm{kHz}$ has $8 \%$ error at $10 \mathrm{kHz}$; however, upsampling by a factor of 3 reduces the error to below $1 \%$.

\subsection{Release Device Simulator Module}

3.2.1. Explicit FEA Model. We made an explicit FEA model for the PPSS design using Abaqus Explicit (version 6.10), as shown in Figure 11. To reduce the computational cost, only a quarter of PPSS was modelled. Symmetric boundary conditions are applied to the two cut sections on the $X Z$ and $Y Z$ planes. For the remaining surfaces, boundary conditions are not applied because they are free. The two ends of the resonator are fixed to the sacrificial plate and the center of ALU bench, respectively, by using surface-based tie constraint. For the impact between the projectile and the sacrificial plate, general contact algorithm based on penalty method is utilized.

The elastic material properties are shown in Table 4 and the plastic properties of SS400 are as follows: $230 \mathrm{MPa}$ at $0 \%$ (yield stress at zero plastic strain) and $415 \mathrm{MPa}$ at $0.2 \%$. The plastic properties between the two provided points are linearly interpolated by Abaqus Explicit.

The elements used in the model are shown in Table 5. The element size should be determined considering that at least ten nodes per wavelength are necessary for correct modelling of wave propagation [47]. There are three types of waves which may frequently occur in aerospace structures: quasi-longitudinal, transverse (shear), and bending waves. Longitudinal wavelength $\lambda_{L}$, transverse wavelength $\lambda_{T}$, and 


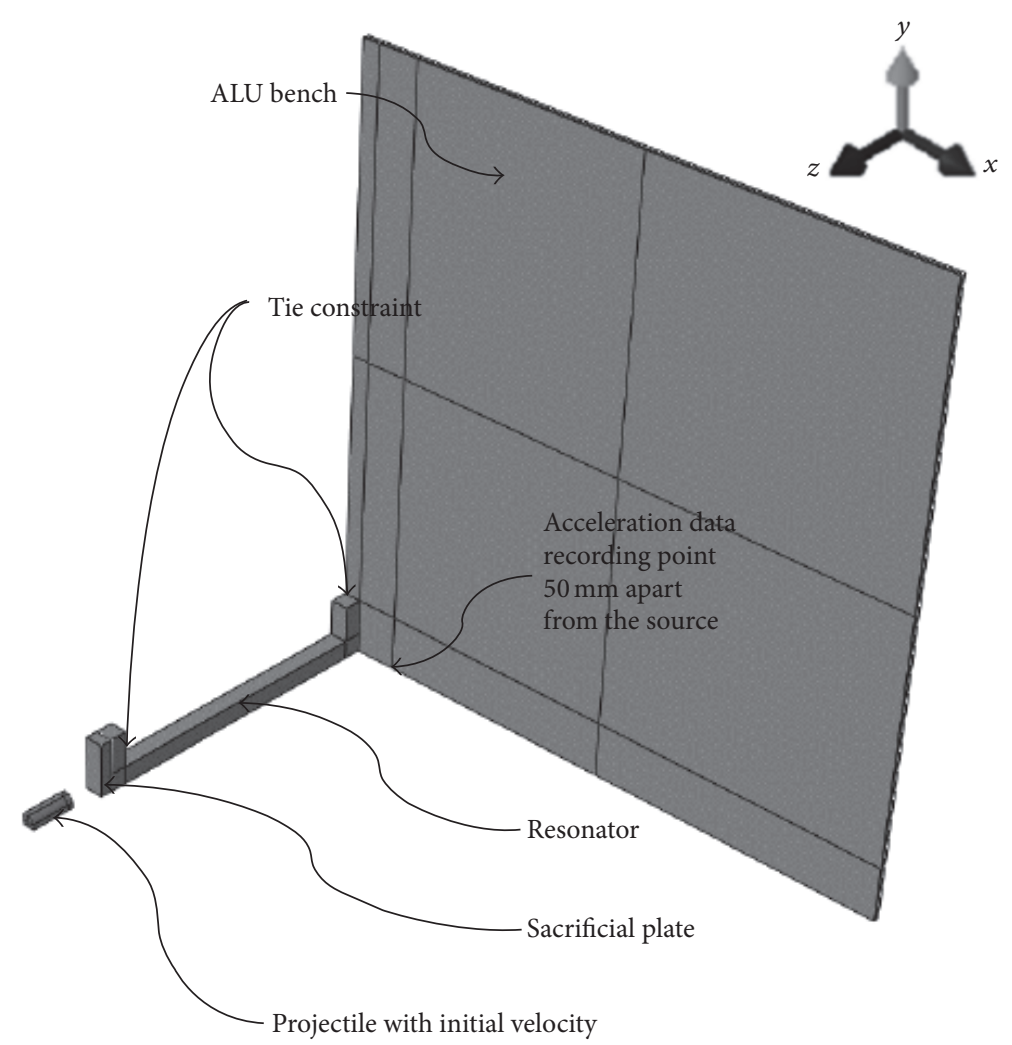

FIGURE 11: Schematic view of explicit FE model and boundary conditions for PPSS design.

TABLE 4: Material properties of resonator components.

\begin{tabular}{lcccc}
\hline Part & Material & $E^{\mathrm{a}}$ & $\rho^{\mathrm{b}}$ & $\nu^{\mathrm{c}}$ \\
\hline Test bench & Aluminum & 72 & 2800 & 0.33 \\
\hline Resonator & SCM435 & & & \\
Projectile & SNCM440 & 205 & 7850 & 0.29 \\
Sacrificial & SS400 & & & \\
\hline
\end{tabular}

${ }^{\mathrm{a}}$ Elastic modulus (GPa).

${ }^{\mathrm{b}}$ Density $\left(\mathrm{kg} / \mathrm{m}^{3}\right)$.

${ }^{c}$ Poisson's ratio.

bending wavelength $\lambda_{B}$ can be determined based on the following equations:

$$
\begin{aligned}
& \lambda_{L}=\frac{1}{f} \sqrt{\frac{E}{\beta \rho}} \\
& \lambda_{T}=\frac{1}{f} \sqrt{\frac{G}{\rho}} \\
& \lambda_{B}=\sqrt{\frac{2 \pi}{f}}\left(\frac{E h^{3} / \beta 12}{\rho h}\right)^{0.25},
\end{aligned}
$$

where $f, \beta, G$, and $h$ are frequency, a coefficient of structure configuration, shear modulus, and the thickness of a beam or a plate, respectively [48]. $\beta$ is one but is $1-v^{2}$ for a plate ( $\nu$ is Poisson's ratio). According to the SRS requirements in Table 2,
TABLE 5: Elements and their size.

\begin{tabular}{lccc}
\hline Component & Type $^{\mathrm{a}}$ & Size $(\mathrm{mm})$ & Wavelength $^{\mathrm{b}}(\mathrm{mm})$ \\
\hline Sacrificial plate & C3D8R $^{\mathrm{c}}$ & $1 \times 1 \times 1$ & 511 \\
Resonator & & $5 \times 5 \times 5$ & \\
& & & $507^{\mathrm{e}}$ \\
ALU bench & S4R $^{\mathrm{d}}$ & $7.5 \times 7.5$ & $69.7^{\mathrm{f}}$ \\
\hline
\end{tabular}

${ }^{a}$ Regardless of element type, enhanced hourglassing option was applied for accurate bending analysis [34].

${ }^{\mathrm{b}}$ Wavelengths at $10 \mathrm{kHz}$ which is the highest frequency of SRS analysis.

${ }^{\mathrm{c}} \mathrm{A}$ first-order solid element with reduced integration.

${ }^{\mathrm{d}}$ A first-order shell element with reduced integration.

${ }^{\mathrm{e}}$ Longitudinal wavelength.

${ }^{\mathrm{f}}$ Bending wavelength.

the corresponding wavelengths were calculated, as shown in Table 5. Subsequently, the element sizes were determined considering the following: the wavelengths, plastic deformation of the sacrificial plate, and the tie constraints.

The most critical consideration when applying explicit FEA to pyroshock is sampling and aliasing. To satisfy the stability limit of explicit FEA [34], quite small time increments are inevitable in explicit FEA. Because recording all of the data is practically impossible due to the small time increments, the common process of data recording in explicit FEA is to sample data with much larger time intervals than the original time increments. Thus, sampling in explicit FEA must be performed according to Shannon's sampling 


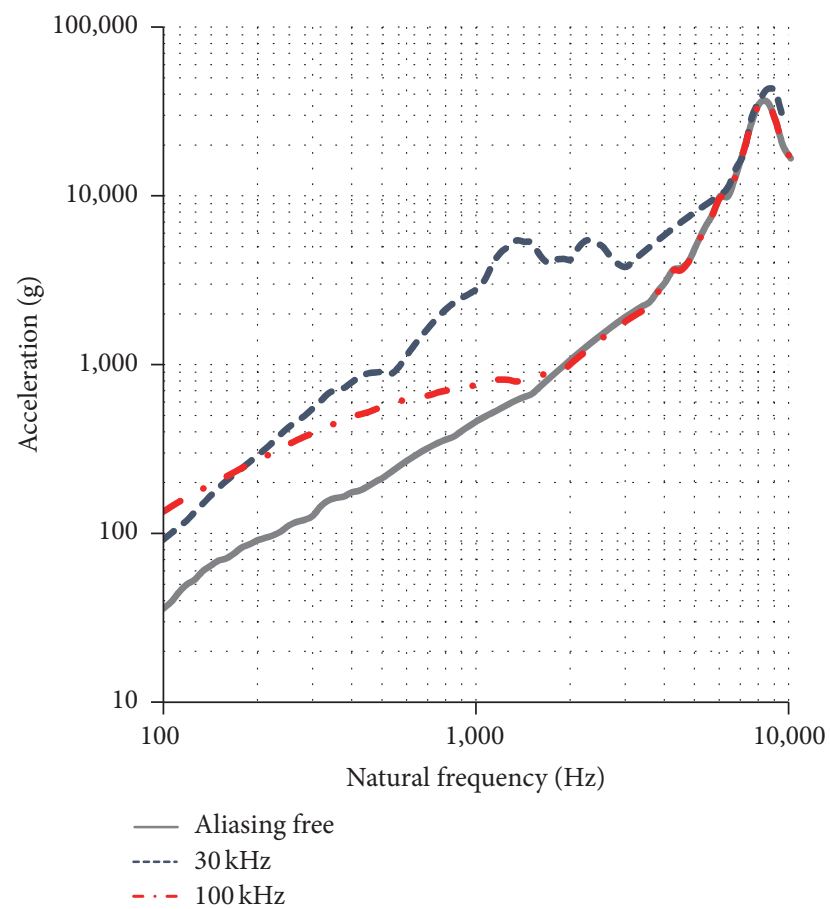

FIGURE 12: SRS distortion due to aliasing in the explicit FEA model.

theorem. However, in the case of pyroshock, it is difficult to satisfy Shannon's theorem due to its broadband high frequency feature. Furthermore, force as well as acceleration obtained by explicit FEA inherently oscillates severely with high frequency numerical noises compared to velocity and displacement [49]. Nevertheless, all of the previous researchers who introduced explicit FEA to pyroshock did not recognize this sampling issue $[19,21,50-53]$. At first, we also cannot recognize the effect of aliasing on explicit FEA. During the parameter study using the model described in Figure 11, we could not find the trends because aliasing distorts acceleration time history in a random manner. Thus, to investigate the effect of aliasing on SRS analysis, we obtained three SRSs from the PPSS model at the measurement point (50 $\mathrm{mm}$ apart from the resonator), as shown in Figure 12. All of the conditions were identical except for a sampling rate. Aliasing-free SRS was obtained by recording the whole acceleration signal: no aliasing due to no sampling. Sampling rate of $100 \mathrm{kHz}$ satisfies the sampling requirement for the SRS analysis whose highest frequency is $10 \mathrm{kHz}[44,46]$; however, the signal contents below $2 \mathrm{kHz}$ were severely distorted (the maximum error was $200 \%$ ).

There are two strategies for removal of aliasing in explicit FEA: built-in antialiasing (AA) filter [49] and Diehl's procedure [45]. The first one is supported in Abaqus Explicit but the default built-in AA filter cannot satisfy the AA filter requirement recommended by IEST-RD-DTE012.2 [31] (see Table 2). Thus, we designed eighth order infinite impulse response (IIR) Butterworth filter with sampling rate of $100 \mathrm{kHz}$ to satisfy the AA filter requirement. The designed filter satisfies all of the AA filter requirements as shown in Figure 13. The key principle of Diehl's procedure is whole data
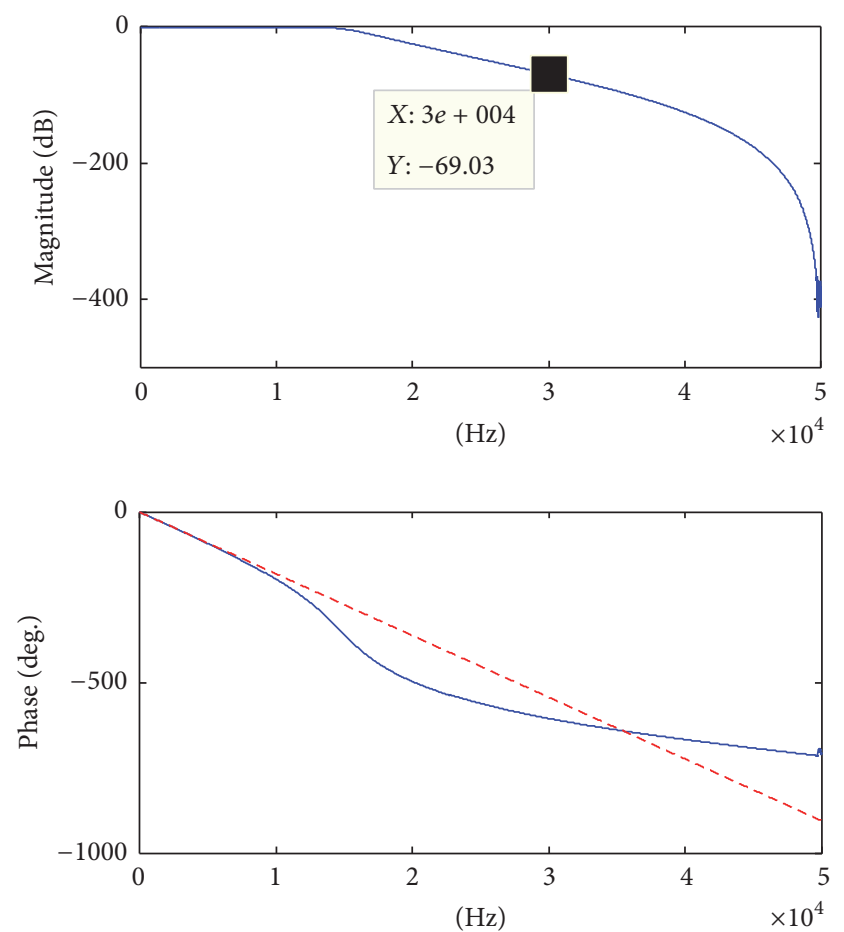

FIGURE 13: Bode plot of the designed eighth order IIR Butterworth filter. (a) Magnitude. (b) Phase.

recording. After whole data recording, the signal is splineinterpolated with the minimum of the time increments. The final step is decimation to reduce the size of data. However, decimation is considered as optional because an acceleration time history is recorded at only one point: the data size is a few megabytes. Figure 14 proved that both can remove aliasing. The two SRSs from Diehl's procedure and whole data recording are perfectly matched while aliasing cannot be prevented perfectly in some frequencies by the built-in eighth order IIR Butterworth filter. Also, the built-in filter should be redesigned if the highest frequency of SRS is changed. Thus, during the design process, we removed aliasing by using Diehl's procedure.

3.2.2. Design Result. According to the design procedure shown in Figure 10, the major design variables, $v_{P}$ and $L_{R}$, were determined to be $23.13 \mathrm{~m} / \mathrm{s}$ and $0.2744 \mathrm{~m}$, respectively. The values of the other variables are the same as those described in Table 3. The response of the obtained PPSS design satisfies the tolerance and magnitude conditions (Figure 15), thereby being effectively equivalent to the target environment (the corresponding acceleration time history is shown in Figure 16). In a qualitative view, the acceleration fields shown in Figure 17 agree well with the radial propagation characteristics of point sources. Thus, based on this design result, we determined the air gun capacity.

3.3. Wrap-Around Breech Air Gun. The design variables of the wrap-around breech are shown in Figure 18 and can be determined using the Seigel's PPIG gun model [27]. This model has been used by many researchers $[35,37,38,54]$ 


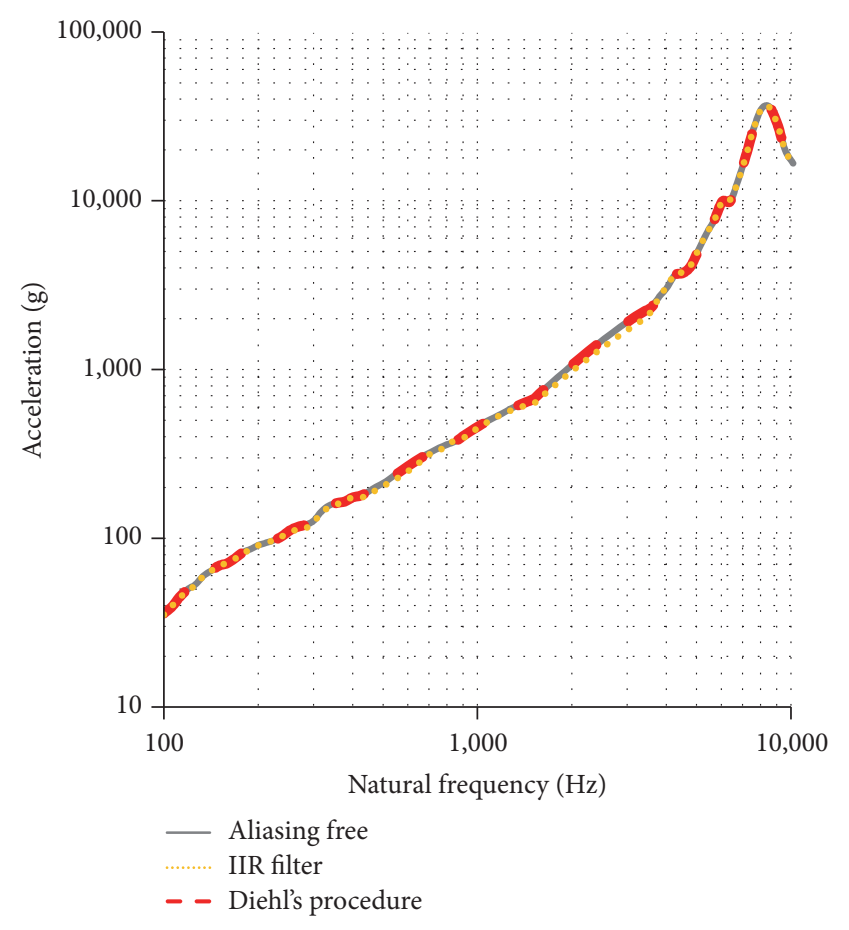

FIgURE 14: Comparison of Diehl's procedure and eighth order IIR Butterworth filter with sampling rate of $100 \mathrm{kHz}$.

and is a well-developed gas gun model. This model was derived assuming the breech length is infinite: the breech length $L_{\mathrm{Br}}$ should be long enough to be effectively infinite and the amount of gas should be sufficient. In general, the rarefactions reflected from the breech end cause the back pressure $p_{b}$ to drop when these reflections reach the rear end of the projectile. To prevent this back pressure drop, the barrel length $L_{B}$ should be less than six times the breech length $L_{\mathrm{Br}}$ [54]. The second assumption is satisfied for $v_{P} / a_{0}<0.4$, if the mass of the gas $M_{G}$ is larger than one-eighth of the projectile mass $M_{P}$ : here, $a_{0}$ is the initial sound velocity in the breech. Seigel's model is described as follows:

$$
\begin{aligned}
& M_{P} \frac{d v_{P}(t)}{d t}=A_{B}\left[p_{b}(t)-p_{f}(t)\right], \\
& p_{b}(t)=p_{0}\left(1-\frac{\gamma-1}{2} \frac{v_{P}(t)}{a_{0}}\right)^{2 \gamma /(\gamma-1)}, \\
& p_{f}(t)=p_{\text {atm }}\left\{1+\left[\frac{v_{P}(t)}{a_{0}}\right]^{2} \frac{\gamma(\gamma+1)}{4}\right. \\
& \left.+\gamma \frac{v_{P}(t)}{a_{0}} \sqrt{1+\left(\frac{\gamma+1}{4}\right)^{2}\left[\frac{v_{P}(t)}{a_{0}}\right]^{2}}\right\},
\end{aligned}
$$

where $A_{B}$ is the inner area of the barrel; $p_{f}$ is the resisting pressure due to the air in front of the projectile; $p_{0}$ and $p_{\text {atm }}$ are breech and atmospheric pressures, respectively; $\gamma$ is the ratio of specific heats (for air, $\gamma=1.4$ ). We used forward finite

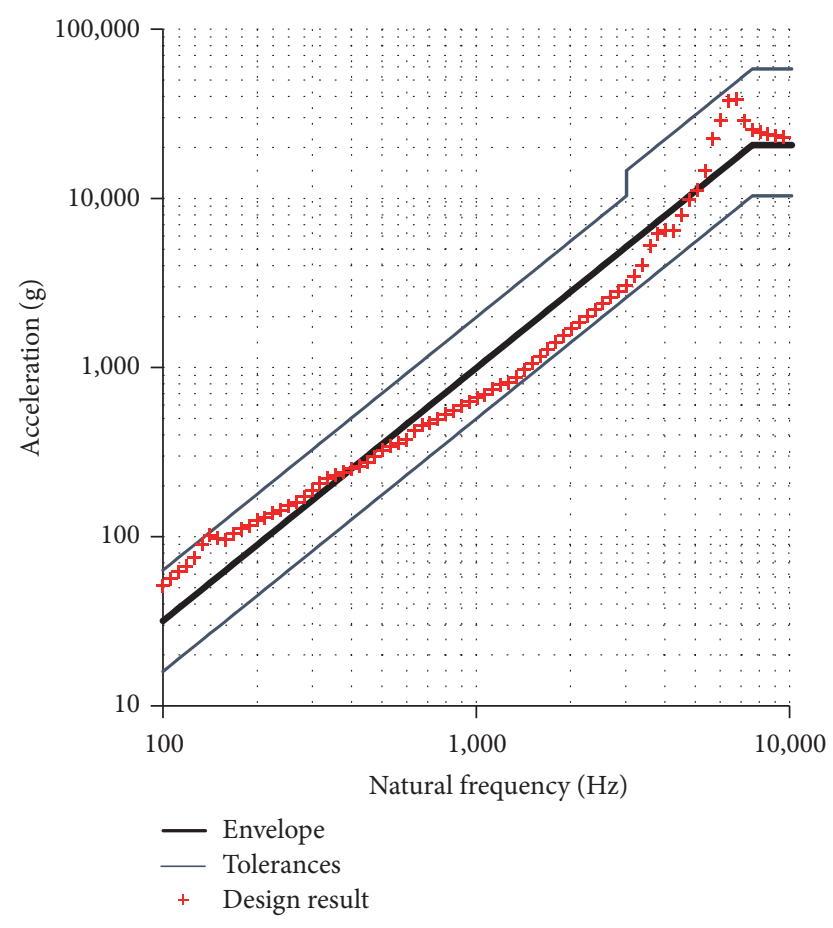

FIGURE 15: SRS of the proposed design.

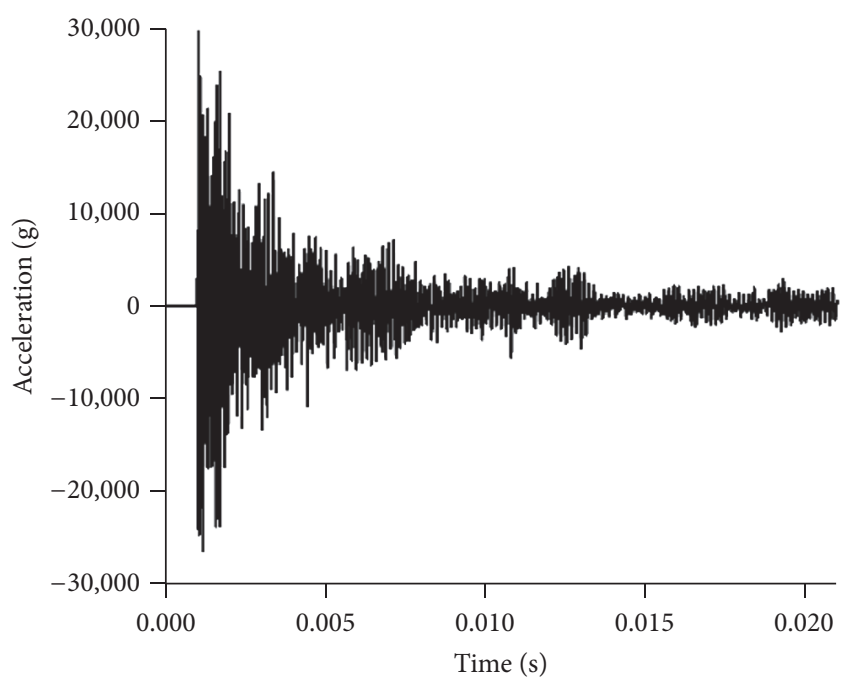

FIGURE 16: Corresponding acceleration time history to the SRS shown in Figure 14.

difference method with a time interval of $10 \mu$ s to solve this model, as follows:

$$
v_{P}(t+\Delta t)=v_{p}(t)+\Delta t A_{B}\left[p_{b}(t)-p_{f}(t)\right] .
$$

And at the same time, $L_{B}$ is determined by

$$
L_{B}(t+\Delta t)=L_{B}(t)+\Delta t v_{p}(t) .
$$

For the provided values of $M_{P}$, the projectile diameter, $\Phi_{P}$, and the target velocity, $v_{\text {target }}$, the design variable set $\left\{p_{0}, L_{B}, \Phi_{\mathrm{Br}}, L_{\mathrm{Br}}\right\}$ are determined by the design steps of the wrap-around breech air gun. 


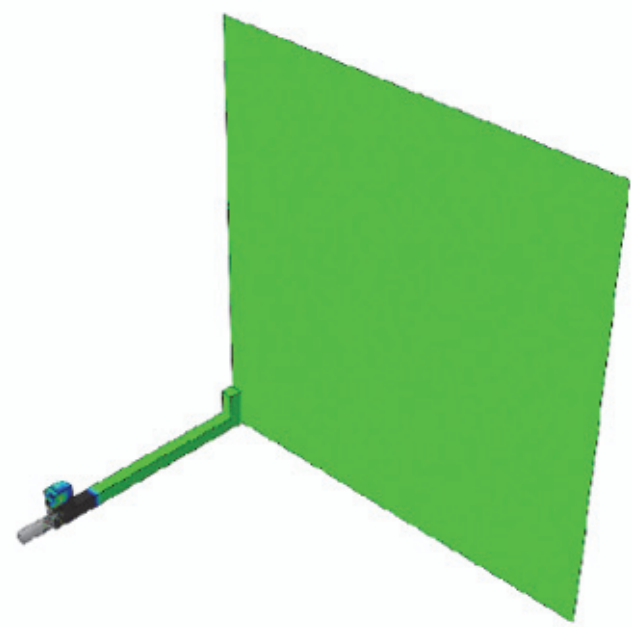

$1.01 \mathrm{~ms}$

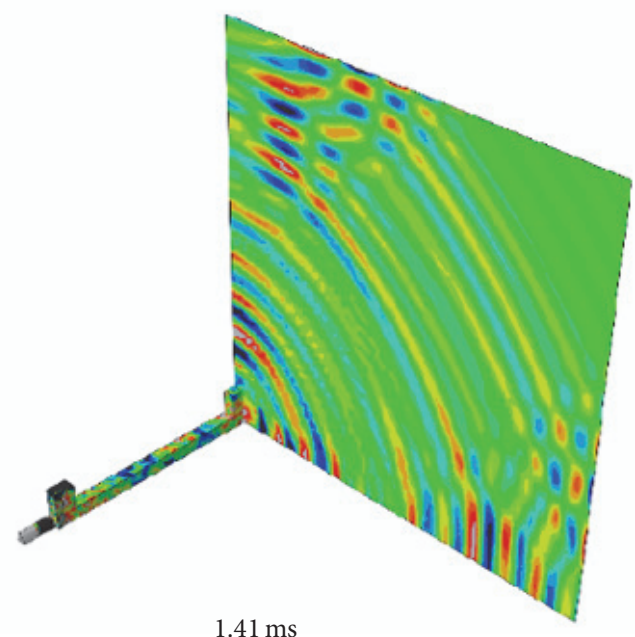

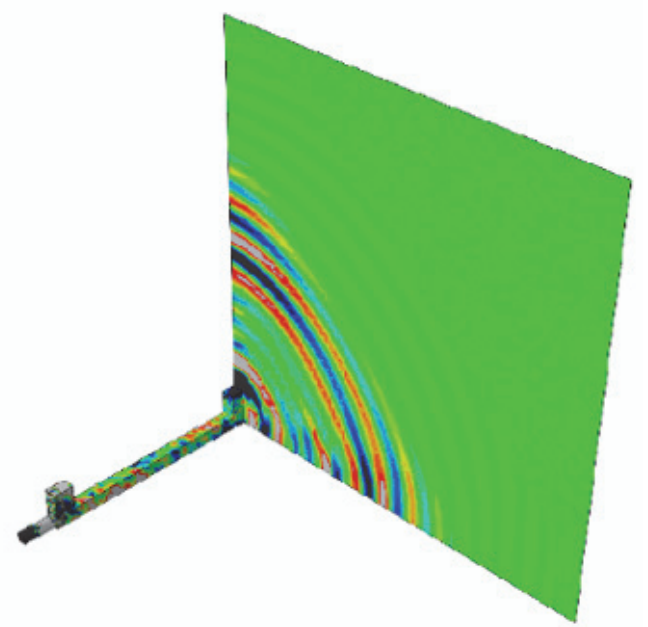

$1.21 \mathrm{~ms}$

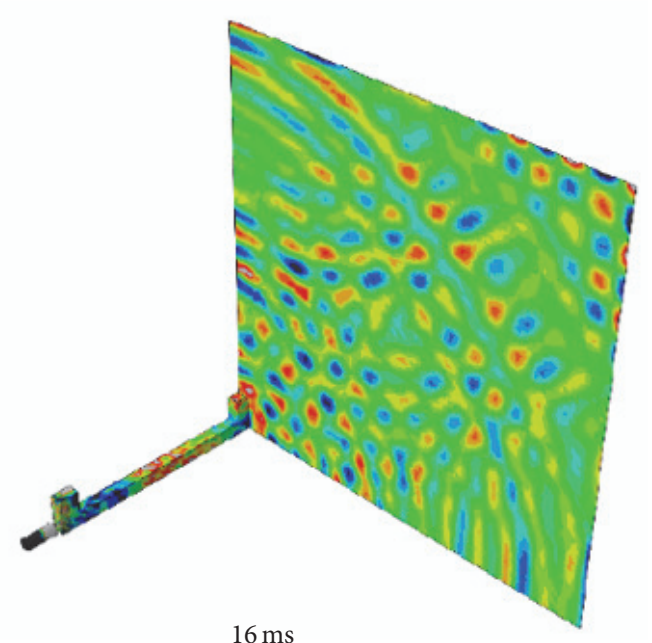

FIGURE 17: Acceleration contour plots of the proposed design result. follows.

Design steps of the wrap-around breech air gun are as

(1) Set the initial breech pressure $p_{0}$.

(2) For the target velocity $v_{\text {target }}$, solve (7) and (8) until $\left|v_{P}(t)-v_{\text {target }}\right| / v_{\text {target }}<e_{\text {target }}\left(e_{\text {target }}\right.$ was set to 0.01 in this study.).

(3) Determine the breech length $L_{\mathrm{Br}}$ such that $L_{B}<6 L_{\mathrm{Br}}$.

(4) Solve (9) considering that $R_{M}=M_{G} / M_{P}>1 / 8$ for $v_{p} / a_{0}<0.4$.

( $\Phi_{\mathrm{Br}}$ and $L_{\mathrm{Br}}$ are the diameter and length of the breech). In the first step, the maximum operating pressure (MOP) of a regulator should be considered because its $\mathrm{MOP}$ is generally less than that of the other pneumatic components. We used PER2020-02 which is a high precision regulator made by TPC Mechatronics corp. $p_{0}$ was determined to be $0.6 \mathrm{MPa}$ (gage) considering the pressure distributed in our department is $0.8 \mathrm{MPa}$ (gage) and the MOP of PER2020-02 is limited to below $85 \%$ of supply air pressure. In the second step, some margin should be added to the required velocity $(23.1337 \mathrm{~m} / \mathrm{s})$ when determining $v_{\text {target }}$. We set the maximum velocity of the projectile as $30 \mathrm{~m} / \mathrm{s}$ for sufficient adjustability of the projectile velocity. In addition, because Seigel's model cannot consider the friction between the projectile O-rings and the barrel, we included a margin of $50 \%$ for the friction: $v_{\text {target }}=45 \mathrm{~m} / \mathrm{s}$. Solving (7) and (8), $L_{B}$ of $0.650 \mathrm{~m}$ satisfies $v_{\text {target }}$. In the third and fourth steps, the dimensions of the breech are determined. The condition for the first assumption gives $L_{\mathrm{Br}}$, and $\Phi_{\mathrm{Br}}$ is determined using both the ideal gas law and the condition for the second assumption, as follows:

$$
\Phi_{\mathrm{Br}}=\sqrt{\Phi_{B, o}^{2}+\frac{4}{\pi} \frac{M_{P} R_{M} a_{0}^{2}}{\gamma p_{0} L_{\mathrm{Br}}}},
$$

where $R_{M}$ is the ratio of $M_{G}$ to $M_{P}$ and $\Phi_{B, o}$ is the outer diameter of the barrel. $R_{M}$ can be any value as long as the second assumption is satisfied. According to the third 


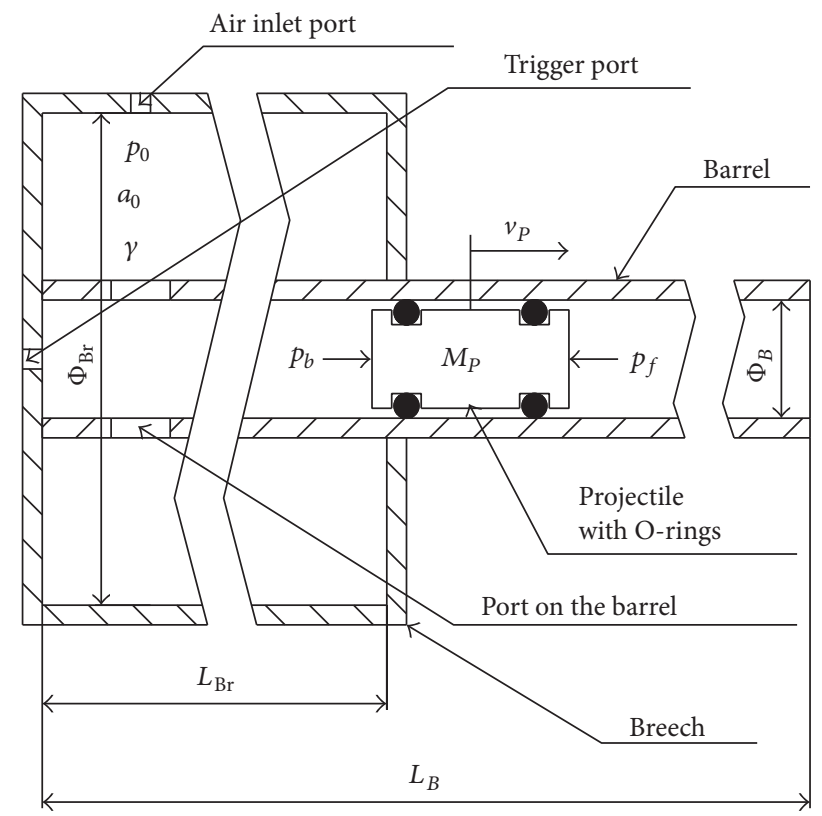

FIGURE 18: Schematic diagram of the wrap-around breech mechanism and its design variables.

and fourth steps, $L_{\mathrm{Br}}$ and $\Phi_{\mathrm{Br}}$ were determined as $0.190 \mathrm{~m}$, $0.110 \mathrm{~m}$.

Figure 19 shows both the design result of the wraparound breech type air gun and the schematic diagram of the corresponding pneumatic circuit. The operation order of the air gun is described as follows.

(1) Locate the projectile at the ports on the barrel.

(2) Close all of the valves.

(3) Fill the breech up to the desired pressure by opening the first valve. If the pressure reaches the desired value, close the first valve.

(4) Fire the projectile by opening the second valve. After a test is finished, close the second valve.

(5) Relocate the projectile by opening both the third and fourth valves.

(6) Repeat the steps from the second for a new test.

Releasing the compressed air in the breech is triggered by the compressed air flow from the second port to the third port. This removes the need for an air pulse generator, thereby simplifying the conventional wrap-around mechanism. Furthermore, no electronic control is required.

Note that a lubricator should be included to minimize the effect of friction. We used quad-rings which were specially developed for dynamic sealing. The size, material, installation chamfers, and grooves of the quad-rings were determined so as to be compatible with KS B 2799:1997 [55] and KS B 2805:2002 [56]: P-16 Viton quad-ring and chamfers whose depth and angle are $2 \mathrm{~mm}$ and $15^{\circ}$. Additionally, to reload the projectile at the ports on the barrel, a vacuum generator was utilized.
3.4. Instrumentation. The instrumentation requirements described in Table 2 were suggested based on a strong analog antialiasing (AAA) filter strategy. Although this strategy provides good aliasing removal, AAA filters are physically large, expensive, and inherently limited in cutoff capability and phase matching [46].

However, there is a much more effective strategy for aliasing removal: the oversampling/finite impulse response (FIR) filter approach [46]. A delta-sigma $(\Sigma \Delta)$ ADC was developed for the oversampling/FIR filter approach. A $\Sigma \Delta$ ADC has an essentially flat $( \pm 0.01 \mathrm{~dB})$ response for frequencies from zero to $0.453 f_{s}$. Aliasing-free data are provided for frequencies below $0.453 f_{s}$ especially. The additional advantage of a $\Sigma \Delta$ $\mathrm{ADC}$ is that it has a constant-delay or linear-phase response. Because the oversampling/FIR filter approach can provide an almost ideal data acquisition for pyroshock measurement, we used NI USB-4431 which is a $\Sigma \Delta \mathrm{ADC}$ with a maximum sampling rate of $102.4 \mathrm{kHz}$.

The key point of accelerometer selection is to suppress accelerometer resonance. NASA-STD-7003A reported that there are two types of accelerometers applicable to pyroshock measurement [29]: accelerometers with built-in or attached mechanical filters and piezoresistive (PR) accelerometers with natural frequencies in excess of $1 \mathrm{MHz}$ and shock limits of $200,000 \mathrm{~g}$. Generally, it is difficult for other nations except for the USA to purchase PR accelerometers due to the international traffic in arms regulation (ITAR). In contrast, there are many purchasable piezoelectric (PE) accelerometers. Kolaini et al. investigated the performance of the five PE accelerometers commonly used for pyroshock measurement [57]: Endevco7255A-01, Endevco 2255M5A, Endevco 2255B01, PCB 350C02, and Kistler 8742. He reported that PCB $350 \mathrm{C} 02$ had the best performance among these accelerometers. Thus, PCB 350D02, the updated version of PCB 350C02, was applied to the PPSS (all of the accelerometer requirements described in Table 2 are also satisfied).

\section{Experimental Verification and Discussion}

Based on the design result, the prototype and the corresponding pneumatic console were fabricated as shown in Figure 20. ALU bench is suspended by steel chains and turnbuckles, and the resonator and ALU bench are joined by two M6 bolts. The sacrificial plate is also bolted to the impacted end of the resonator. To adjust the position of the air gun, the air gun is supported by a scissor lift.

To verify the PPSS, we performed three tests under the same conditions as those of the design result and the three SRSs are shown in Figure 21 (denoted as test 1, test 2, and test 3). The three SRSs show that the PPSS achieves the target environment and its simulated environment is near-field. Thus, it is proved that the PPSS can simulate stress wave propagation near a point source without an explosive charge. Considering that near-field simulation is only provided by pyrotechnically excited resonant fixture techniques, the PPSS can be a more efficient alternative for near-field simulation. Indeed, due to the nature of explosion, pyrotechnical excitation is dangerous and also has low repeatability. Note that the PPSS can simulate more intensive pyroshock simply by increasing the velocity 


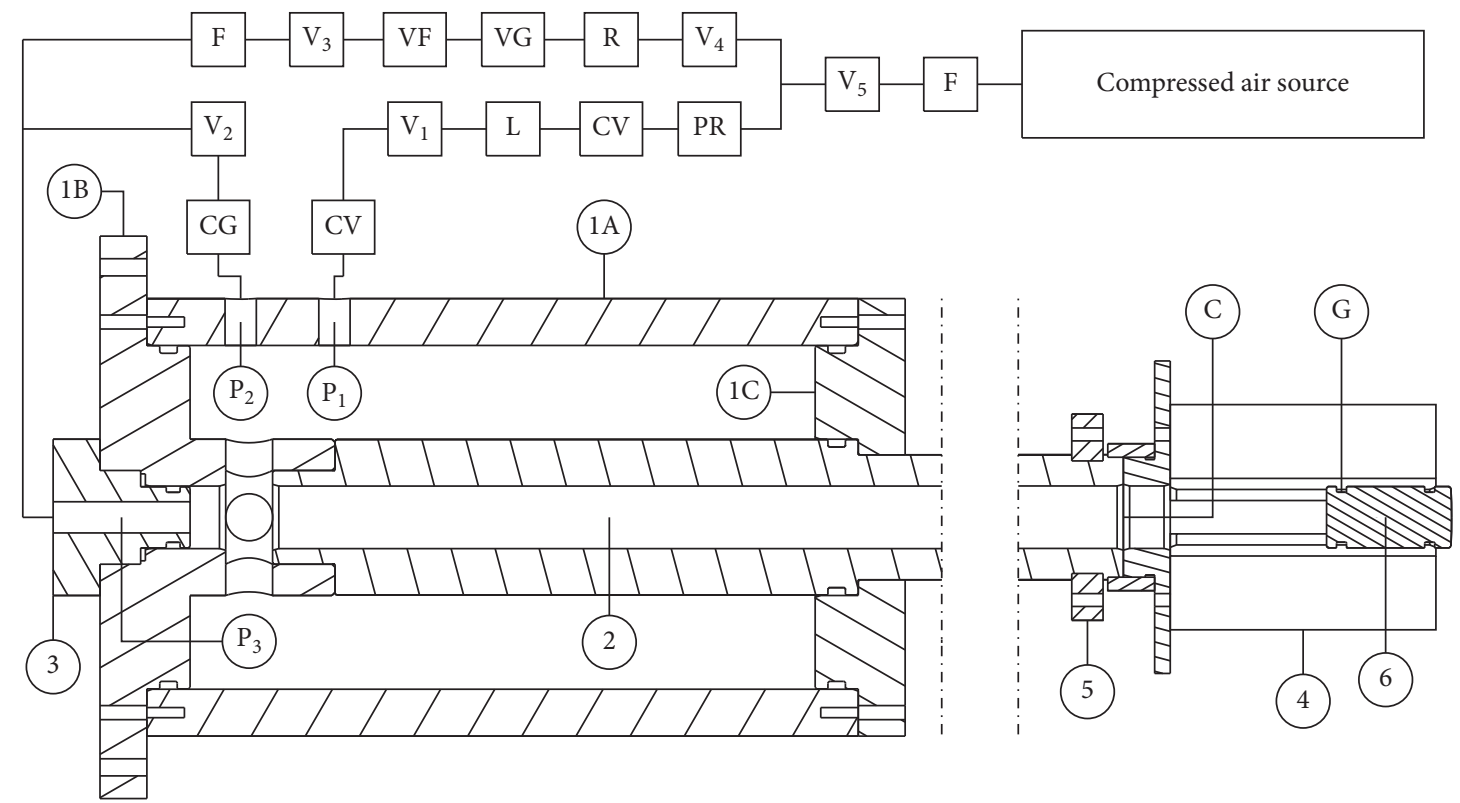

FIGURE 19: The designed wrap-around breech air gun and the schematic diagram of its pneumatic circuit. F: filter, $V_{i}: i$ th valve, PR: precision regulator, R: regulator, CV: check valve, VG: vacuum generator, L: lubricator, VF: filter for the vacuum generator, and CG: compound gage; 1: breech, 2: barrel, 3: detachable loader, 4: muzzle, 5: connector, 6: projectile, O: O-ring, $\mathrm{P}_{i}$ : ith port, G: groove for an O-ring, and C: chamfer for an O-ring.

of the projectile and shortening the resonator makes its knee frequency higher.

With regard to the repeatability of the PPSS, the three SRSs match well together except for low frequencies. The inconsistency in low frequencies is considered to be caused by imperfect recovery of zero-shifted acceleration data. Zeroshift distorting the low frequency portion of SRS commonly occurs when measuring near-field pyroshock with accelerometers due to the intensive and high frequency nature of near-field pyroshock [16, 29, 31, 32, 58, 59]. Because the simulated environment by the PPSS is also near-field, zero-shift occurred during measurement despite use of the isolated accelerometer PCB 350D02 which suppresses both zero-shift and accelerometer resonance. Thus, to recover the low frequency portion of our acceleration data, the multipass mean filter method [58] with window size 8 and 10 passes was applied to all of the experimental data. Note that the distortion by zero-shift was removed after doubly integrating the acceleration data to remove only the distortion, referring to Edwards' suggestion [59]. However, the distortion remained slightly and the remaining distortion seems to cause the inconsistency in low frequencies.

Under the identical conditions to the tree tests, we performed an additional test on the SIA tried during Viking program to check the performance of the PPSS as a source isolator evaluator. Barret inserted metal spacers between a separation nut and its mounting structure (Viking lander), thereby reducing the source SRS peak from 9,000 $\mathrm{g}$ to 7,000 $\mathrm{g}$ [11]. Although the reduction by this method is minor, it can be a good example to verify the PPSS. According to Barret's research, we tested the case that two M6 steel washers are inserted between the resonator and ALU bench. As a result, the SRS peak was reduced by approximately $20 \%$ in the same manner as Barret's method (the dotted red line in Figure 21). Considering that it is highly expensive and not repeatable to use actual release devices to evaluate source isolators, applying the PPSS is considered to be much more suitable.

Another important advantage of the PPSS is that the fixture configuration can be freely selected because the release device simulator module simulates an actual source itself. That is, different fixtures can be adopted for simulation of the other structures. Thus, the PPSS can provide more realistic simulation compared to the previous simulators. That is, it is more close to real situations to use a fixture having equivalent bending stiffness to that of the flight structure at which an avionic box is attached. Furthermore, such a characteristic may be a solution to the overtesting issue of the previous simulators based on their vibrating fixtures in that the overtesting is mainly due to the rigidity of the fixtures $[13,60]$. Indeed, the fixture thickness of the PPSS is just $5 \mathrm{~mm}$ while mechanically excited resonant fixtures cannot have the knee frequency of the PPSS because a resonant fixture having the same knee frequency has unrealistic thickness. For example, according to (10), a mechanically excited resonant fixture whose configuration is a beam or a plate should have thickness of $1.90 \mathrm{~m}$ for the knee frequency of the PPSS (about $10 \mathrm{kHz}$ ), when assuming that its length and material are $1 \mathrm{~m}$ and a structural metal, respectively;

$$
f_{\text {knee }}=\frac{22.37}{2 \pi} \sqrt{\frac{E}{12 \rho}} \frac{h}{L^{2}},
$$

where $f_{\text {knee }}, h$, and $L$ are the knee frequency, the thickness, and the length of a plate or beam type resonant fixture. In 


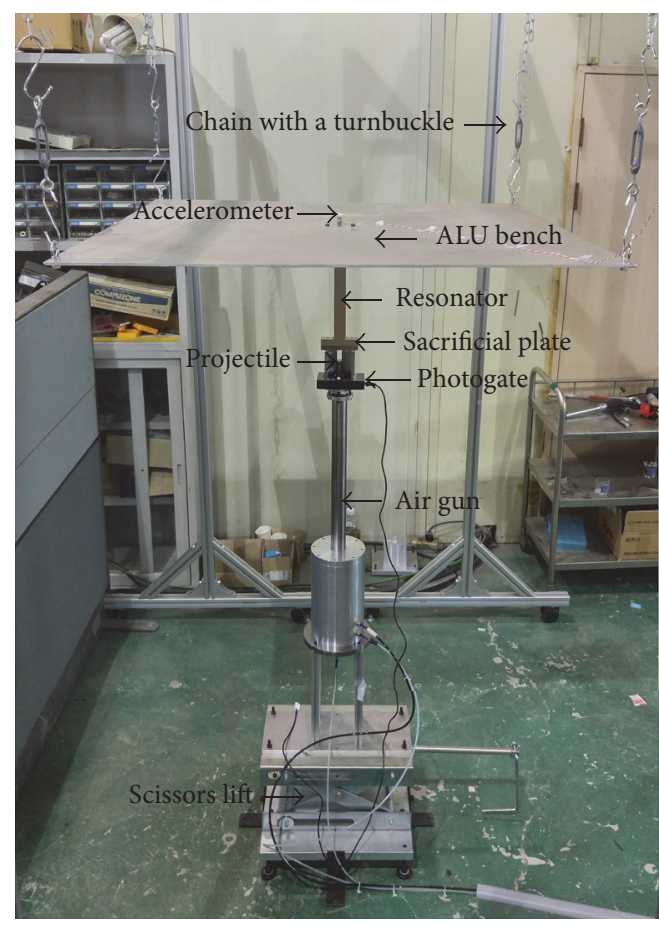

(a)

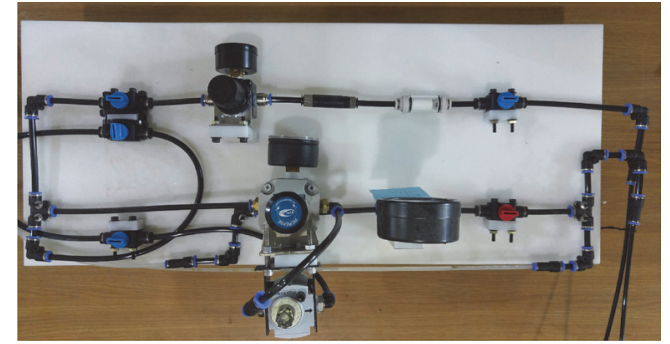

(b)

Figure 20: Fabricated prototype. (a) PPSS. (b) Pneumatic console.

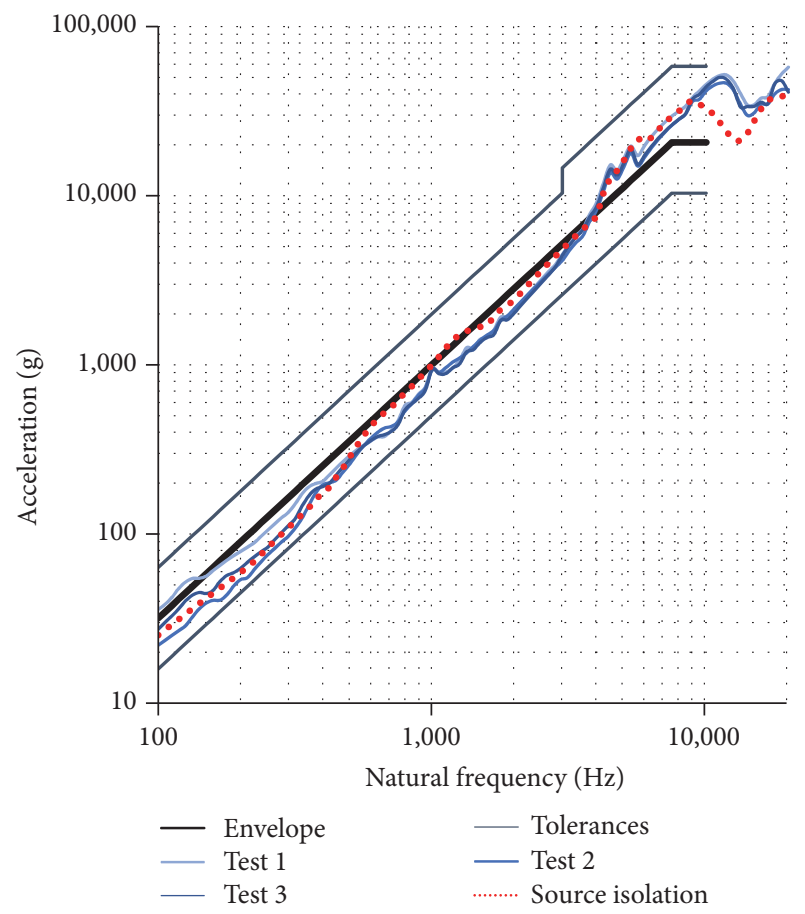

FIGURE 21: Simulated pyroshock environments and the attenuated pyroshock environment by source isolation using washers.

the case that $f_{\text {knee }}$ is $1 \mathrm{kHz}, 0.190 \mathrm{~m}$, relatively thick compared to the fixture of the PPSS, is still required. Note that (10) is frequently used to design mechanically excited resonant fixtures whose type is a plate or a beam $[13,16,26]$. Therefore, to further advance simulation of far- and mid-fields, the concept of the PPSS may be extended to them by using a resonator having low natural frequency.

\section{Conclusion}

We developed the PPSS which simulates a release device itself by using a systematic design procedure based on explicit FEA and Seigel's PPIG model. The prototype provided simulation of a point source and functioned as a performance evaluator of source isolators. Thus, one can develop a source isolator using the PPSS to make a breakthrough in avionics protection against pyroshock. Another important aspect of the PPSS is that its fixture is able to be freely selected for simulation of a structure. Such a characteristic is expected to not only solve the overtesting issue of the previous simulators based on their vibrating fixtures but also provide more realistic simulations of pyroshock. For further improvement of the PPSS, we recommend development of a tunable resonator because the tunable resonator simulates various point pyroshock sources having different knee frequencies.

\section{Competing Interests}

The authors declare that there is no conflict of interests regarding the publication of this paper.

\section{Acknowledgments}

This work was supported by Korea Aerospace Research Institute (no. NRF-2014M1A3A4A04062325). Additional support 
was provided by the National Research Foundation of Korea (NRF) grant funded by the Korea government (MSIP): no. 2010-0028680.

\section{References}

[1] D. K. Stumpf, Titan II: A History of a Cold War Missile Program, University of Arkansas Press, 2000.

[2] N. Butterfield, "Pyrotechnic release device," in Space Vehicle Mechanisms: Elements of Successful Design, P. L. Colony, Ed., John Wiley \& Sons, New York, NY, USA, 1998.

[3] C. J. Moening, "Pyroshock test failures," in Proceedings of the 31st Annual Technical Meeting of the Institute of Environmental Sciences, vol. 3, 1985.

[4] M. A. Talley, "Theory of shock and vibration isolation," in Harri's Shock and Vibration Handbook, A. G. Piersol and T. L. Paez, Eds., McGraw-Hill, 6th edition, 2002.

[5] H. LeKuch, "Shock and vibration isolation systems," in Harri's Shock and Vibration Handbook, A. G. Piersol and T. L. Paez, Eds., McGraw-Hill, New York, NY, USA, 6th edition, 2002.

[6] T. Irvine, "Avionics isolation design guidelines (Revision C)," 2009, http://www.vibrationdata.com.

[7] W. J. Kacena, M. B. McGrath, and W. P. Rader, Aerospace systems pyrotechnics shock data (ground test and flight), vol. 6, 1970 .

[8] J. Meltzer, J. Rossoff, J. Slaughter, and J. Sterhardt, "Structure and materials aspects of the prime flight test vehicle," in Proceedings of the 7 th Structures and Materials Conference, Cocoa Beach, Fla, USA, April 1966.

[9] W. R. Britton and G. K. Jones, "Pyrotechnic shock testing of a full-scale reentry vehicle," The Shock and Vibration Bulletin, vol. 36, part 2, pp. 71-81, 1967.

[10] W. J. Kacena, M. B. McGrath, and W. P. Rader, Aerospace Systems Pyrotechnic Shock Data, vol. I, NASA, 1970.

[11] S. Barret, W. P. Rader, and K. R. Payne, "Viking dynamics experience with application to future payload design," Tech. Rep. NASA-CR-3014, Martin Marietta Corp, Denver, Colo, USA, 1978.

[12] ECSS Secretariat, Space Engineering: Mechanical Shock Design and Verification Handbook, ECSS-E-HB-32-25A, 2015.

[13] Pyroshock Testing Techniques, IEST-RP-DTE032.2, 2009.

[14] J.-R. Lee, C. C. Chia, and C.-W. Kong, "Review of pyroshock wave measurement and simulation for space systems," Measurement: Journal of the International Measurement Confederation, vol. 45, no. 4, pp. 631-642, 2012.

[15] Dynamic Environmental Criteria, NASA-HDBK-7005, 2001.

[16] V. I. Bateman and N. T. Davie, "Pyroshock testing," in Harri's Shock and Vibration Handbook, A. G. Piersol and T. L. Paez, Eds., McGraw-Hill, 6th edition, 2002.

[17] E. Filippi, "Pyroshock simulation using the Alcatel Etca test facility," in Proceedings of the 1st European Conference on Launcher Technology, Toulouse, France, 1999.

[18] G. Deroissart, G. Kouroussis, L. B. Fekih, and O. Verlinden, "A matlab toolbox for shock response analysis dedicated to spatial applications," in Proceedings of the 22nd International Congress on Sound and Vibration (ICSV22 '15), Florence, Italy, July 2015.

[19] S. Kiryenko, G. Piret, and J. Kasper, "ESA/ESTEC shock bench presentation," in Proceedings of the European Conference on Spacecraft Structures, Materials and Mechanical Testing 2005, pp. 1405-1413, Noordwijk, Netherlands, May 2005.
[20] R. Hsieh, R. M. Moore, S. Sroka, J. Lake, C. Stull, and P. Avitabile, "Analysis and dynamic characterization of a resonant plate for shock testing," in Special Topics in Structural Dynamics, Volume 6: Proceedings of the 31st IMAC, A Conference on Structural Dynamics, 2013, Conference Proceedings of the Society for Experimental Mechanics Series, pp. 515-533, Springer, Berlin, Germany, 2013.

[21] M. Jonsson, Development of a shock test facility for qualification of space equipment [M.S. thesis], Division Dynamics, Chalmers University of Technology, Göteborg, Sweden, 2012.

[22] S.-H. Youn, Y.-S. Jang, and J.-H. Han, "Compressed mesh washer isolators using the pseudoelasticity of SMA for pyroshock attenuation," Journal of Intelligent Material Systems and Structures, vol. 21, no. 4, pp. 407-421, 2010.

[23] C. De Fruytier, O. Verlinden, and D. Wattiaux, "Pyroshock simulation for qualification of space electronic equipments," in Proceedings of the Workshop on Spacecraft Shock Environment and Verification, Noordwijk, The Netherlands, 2008.

[24] D. Dilhan, A. Piquereau, L. Bonnes, and J. Van de Veire, "Definition and manufacturing of the pyroshock bench," in Proceedings of the 7th ESA/CNES International Workshop on Space Pyrotechnics, Noordwijk, The Netherlands, 2008.

[25] J. J. Titulaer, B. R. Allen, and J. R. Maly, "An alternative to pyrotechnic testing for shock identification," in Proceedings of the 25th Conference and Exposition on Structural Dynamics, IMAC-XXV, pp. 1-11, Orlando, Fla, USA, February 2007.

[26] V. I. Bateman and F. A. Brown, "Evaluation of shock mitigating materials in a V-band pyroshock environment simulated with a resonant fixture," Journal of the IES, vol. 37, no. 5, pp. 40-45, 1994.

[27] A. E. Seigel, “The theory of high speed guns," NATO-AGARD, Neuilly sur Seine, France, AGARDograph 91, 1965.

[28] D. Dilhan, V. Cipolla, H. Grzeskowiak, N. Cable, and S. Kiryenko, "Pyroshock generation," in Proceedings of the European Conference on Spacecraft Structures, Materials and Mechanical Testing 2005, May 2005

[29] Pyroshock test criteria, NASA-STD-7003A, 2011.

[30] United States Department of Defense, "Environmental engineering considerations and laboratory tests," MIL Technical Standard MIL-STD-810G, 2008.

[31] Institute of Environmental Sciences and Technology, Handbook for Dynamic Data Acquisition and Analysis, IEST-RDDTE012.2, 2006

[32] V. I. Bateman, H. Himelblau, and R. Merritt, "Validation of pyroshock data," Sound and Vibration magazine, March 2012.

[33] ISO, "Mechanical vibration and shock-signal processingpart 4: shock-response spectrum analysis," ISO 18431-4:2007, 2007.

[34] Abaqus Analysis User's Manual, v 6.10, Dassault Systèmes Simulia Corp, Providence, RI, USA, 2010.

[35] J. R. Brown, P. J. C. Chappell, G. T. Egglestone, and E. P. Gellert, "A gas-gun facility for material impact studies using lowvelocity, low-mass projectiles," Journal of Physics E: Scientific Instruments, vol. 22, no. 9, pp. 771-774, 1989.

[36] Z. J. Rohrbach, T. R. Buresh, and M. J. Madsen, "Modeling the exit velocity of a compressed air cannon," American Journal of Physics, vol. 80, no. 1, pp. 24-26, 2011.

[37] I. M. Hatchings and R. E. Winter, "A simple small-bore laboratory gas gun," Journal of Physics E: Scientific Instruments, vol. 8, no. 2, pp. 84-86, 1989. 
[38] G. R. Fowles, G. E. Duvall, J. Asay et al., "Gas gun for impact studies," Review of Scientific Instruments, vol. 41, no. 7, 1970.

[39] N. Bourne, Materials in mechanical extremes: Fundamentals and Applications, Cambridge University Press, Cambridge, UK, 2013.

[40] C. C. Ho, Assembly and commissioning of NAVAL postgraduate school gas gun for impact studies [M.S. thesis], Department Mechanical Engineer, Naval Postgraduate School, Monterey, Calif, USA, 2009.

[41] B. J. Jensen, C. T. Owens, K. J. Ramos et al., "Impact system for ultrafast synchrotron experiments," Review of Scientific Instruments, vol. 84, no. 1, Article ID 013904, 2013.

[42] R. W. White and R. Fowles, "Effect of valve opening time on gas gun performance," Review of Scientific Instruments, vol. 39, no. 9, pp. 1296-1297, 1968.

[43] W. T. Thomson and M. D. Dahleh, Theory of Vibration with Applications, Prentice Hall, 5th edition, 1997.

[44] T. Irvine, An introduction to the shock response spectrum (revision S), 2012, http://www.vibrationdata.com.

[45] T. Diehl, D. Carroll, and B. Nagaraj, "Applications of DSP to explicit dynamic FEA simulations of elastically-dominated impact problems," Shock and Vibration, vol. 7, no. 3, Article ID 931351, pp. 167-177, 2000.

[46] S. Smith, "Shock and vibration data acquisition," in Harri's Shock and Vibration Handbook, A. G. Piersol and T. L. Paez, Eds., McGraw-Hill, 6th edition, 2002.

[47] F. J. Serón, F. J. Sanz, M. Kindelán, and J. I. Badal, "Finiteelement method for elastic wave propagation," Communications in Applied Numerical Methods, vol. 6, no. 5, pp. 359-368, 1990.

[48] L. Cremer and M. Heckl, Structure-Borne Sound: Structural Vibrations and Sound Radiation at Audio Frequencies, Springer, Berlin, Germany, 3rd edition, 2004.

[49] Dassault Systèmes Simulia, Getting Started with Abaqus: Interactive Edition, v6.10, Dassault Systèmes Simulia, Providence, RI, USA, 2010.

[50] M. De Benedetti, G. Garofalo, M. Zumpano, and R. Barboni, "On the damping effect due to bolted junctions in space structures subjected to pyro-shock," Acta Astronautica, vol. 60, no. 12, pp. 947-956, 2007.

[51] D. Wattiaux, O. Verlinden, C. Conti, and C. De Fruytier, "Prediction of the vibration levels generated by pyrotechnic shocks using an approach by equivalent mechanical shock," Journal of Vibration and Acoustics, Transactions of the ASME, vol. 130, no. 4, Article ID 041012, 2008.

[52] J. M. Ndambi, B. Reymen, D. Lecompte, and J. Vantomme, "Numerical simulations of a pyrotechnic shock test," in Proceedings of the 8th International Conference on Structural Dynamics , in Proceedings of the 8th international conference on structural dynamics (EURODYN, Leuven, Belgium, 2011.

[53] R. Velmurugan and E. M. Najeeb, "Study of far-field pyroshock responses of composite panels," Journal of Vibration and Acoustics, Transactions of the ASME, vol. 136, no. 3, Article ID 031014, 2014.

[54] M. J. Gouge, S. K. Combs, P. W. Fisher, and S. L. Milora, "Design considerations for single-stage and two-stage pneumatic pellet injectors," Review of Scientific Instruments, vol. 60, no. 4, pp. 570-575, 1989.

[55] O-rings housings-design criteria, KS B 2799, 1997.

[56] O-ring, KS B 2805, 2002.

[57] A. R. Kolaini, R. Nayeri, and D. L. Kern, "Pyroshock simulation systems: are we correctly qualifying flight hardware for pyroshock environments?" in Proceedings of the 25th Aerospace Testing Conference, October 2009.

[58] T. Irvine, "A mean filter method for removing saturation from pyrotechnic shock pulses," 2008, http://www.vibrationdata.com.

[59] T. S. Edwards, "An improved wavelet correction for zero shifted accelerometer data," Shock and Vibration, vol. 10, no. 3, pp. 159167, 2003.

[60] J. P. Deblois, Analytical and experimental investigation of overtesting during assembly-level shock testing [M.S. thesis], Department of Mechanical \& Industrial Engineering, Concordia University, Montreal, Canada, 2009. 


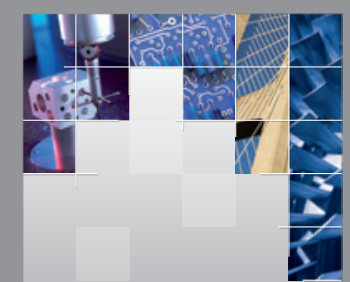

\section{Enfincering}
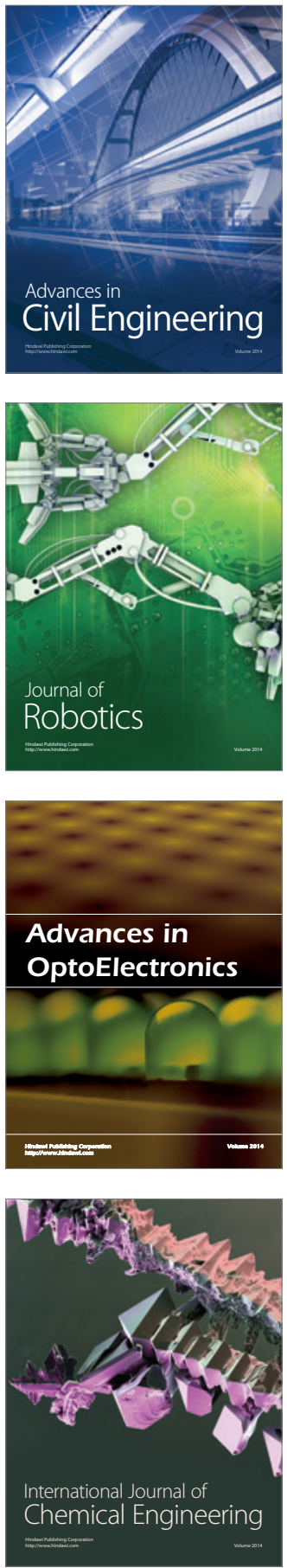

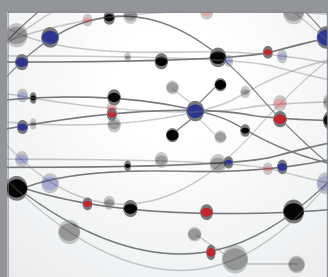

The Scientific World Journal

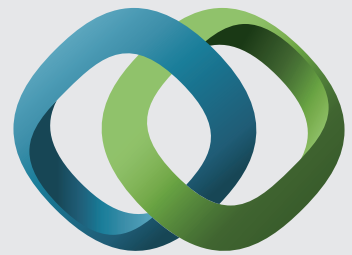

\section{Hindawi}

Submit your manuscripts at

https://www.hindawi.com
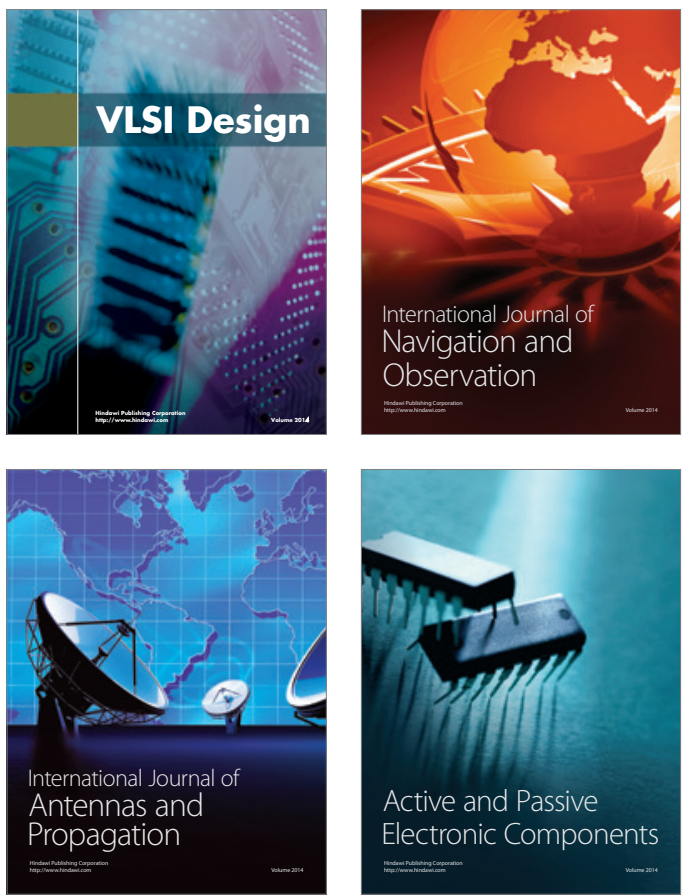
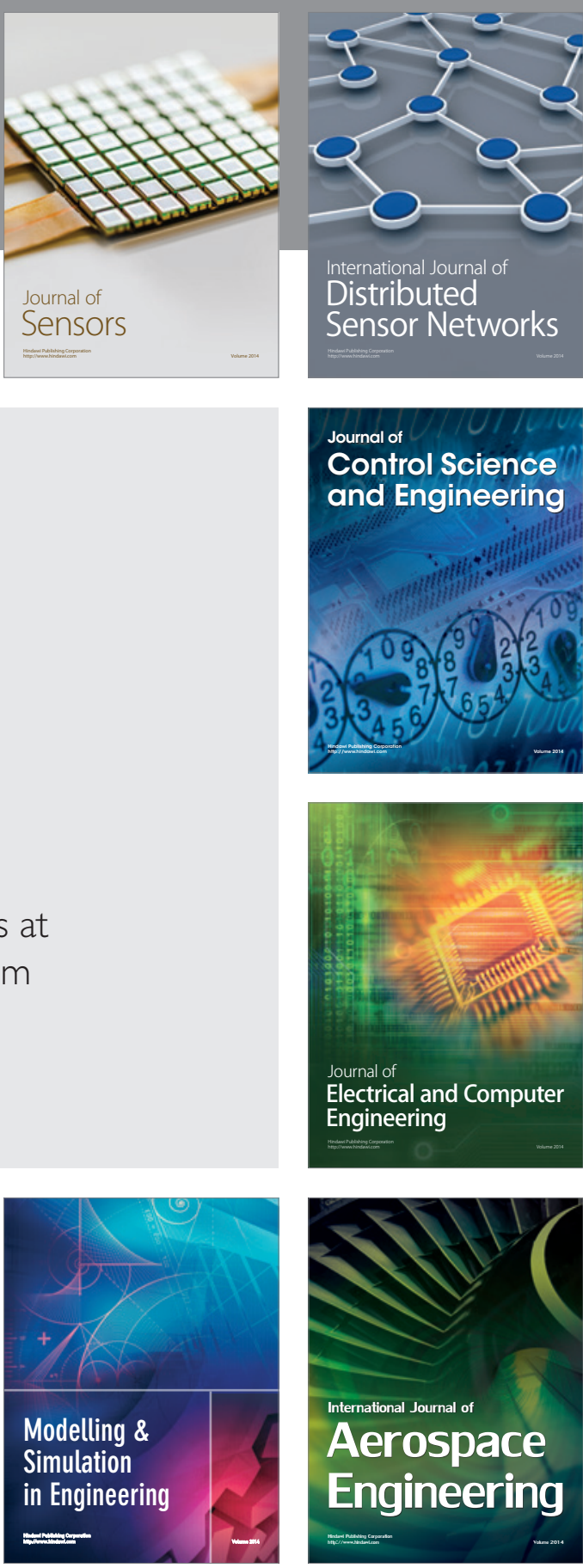

International Journal of

Distributed

Sensor Networks

$-$

Joumal of

Control Science

and Engineering
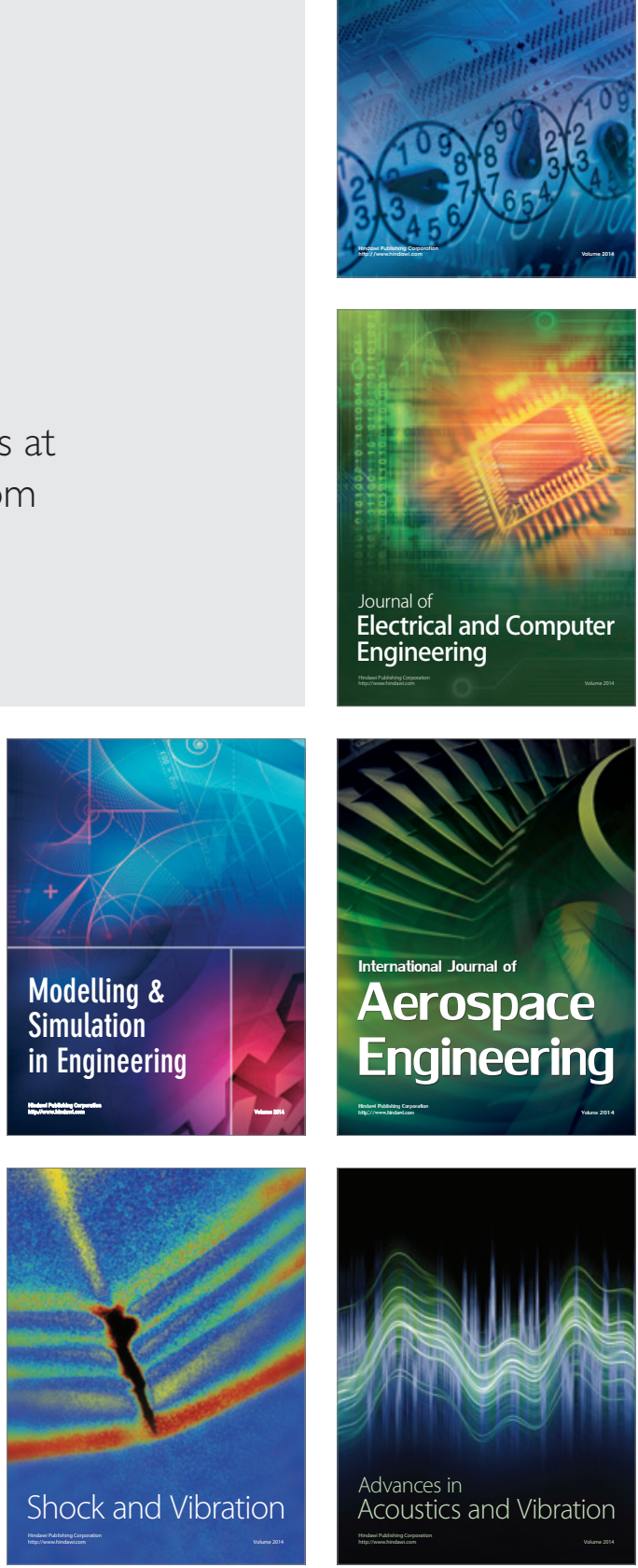